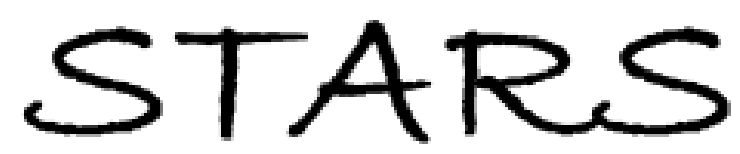

University of Central Florida

STARS

\title{
Stand up and Speak up: Employees' Prosocial Reactions to Observed Abusive Supervision
}

Manuela Priesemuth

University of Central Florida

Part of the Business Administration, Management, and Operations Commons

Find similar works at: https://stars.library.ucf.edu/etd

University of Central Florida Libraries http://library.ucf.edu

This Doctoral Dissertation (Open Access) is brought to you for free and open access by STARS. It has been accepted for inclusion in Electronic Theses and Dissertations, 2004-2019 by an authorized administrator of STARS. For more information, please contact STARS@ucf.edu.

\section{STARS Citation}

Priesemuth, Manuela, "Stand up and Speak up: Employees' Prosocial Reactions to Observed Abusive Supervision" (2012). Electronic Theses and Dissertations, 2004-2019. 4683.

https://stars.library.ucf.edu/etd/4683

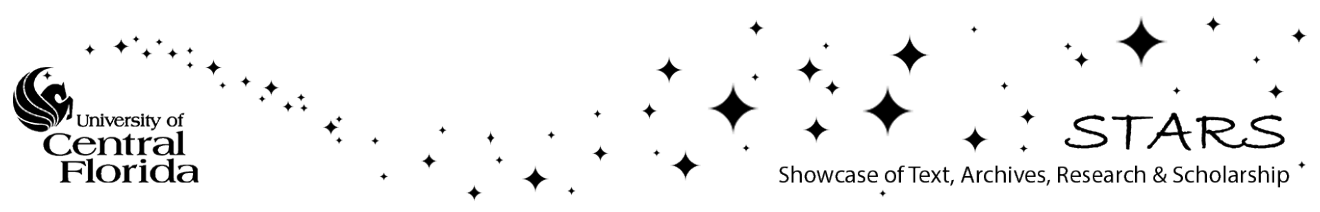


STAND UP AND SPEAK UP: EMPLOYEES’ PROSOCIAL REACTIONS TO OBSERVED ABUSIVE SUPERVISION

by

MANUELA PRIESEMUTH

B.S., College of Saint Mary, 2005

M.B.A., Creighton University, 2007

A dissertation submitted in partial fulfillment of the requirements for the degree of Doctor of Philosophy in the Department of Management in the College of Business Administration at the University of Central Florida Orlando, Florida

\section{Spring Term}

2012

Major Professor: Marshall Schminke 
CC2012 Manuela Priesemuth 


\begin{abstract}
This dissertation examines what happens when employees witness supervisory abuse in the workplace. In particular, it explores whether-and when-employees will respond to witnessing supervisory abuse of a coworker by engaging in prosocial actions aimed at benefitting the target of abuse. In doing so, it extends work on abusive supervision. Traditionally, abusive supervision research has focused on the impact of abuse on the victim him/herself. However, this work explores the impact of abusive supervision on third party observers. In addition, because abusive supervision represents a form of organizational injustice, this dissertation extends both work on abusive supervision and third party reactions to injustice by considering the positive, prosocial reactions abuse might trigger in employees.
\end{abstract}




\section{ACKNOWLEDGMENTS}

First, I would like to thank my dissertation chair, Marshall Schminke, for his time, effort, guidance, and patience throughout the process of completing not only the dissertation but the Ph.D. program as a whole. Furthermore, I would like to thank my committee members Maureen Ambrose, Robert Folger, and Gary Latham for their advice and directions with this and many other projects. I would also like to express the same gratitude to Robert Moorman who has provided me with insights and advice for the profession from the very beginning. My appreciation also goes to all of my classmates in the Ph.D. program. Specifically, I would like to acknowledge my cohort member Alex Vestal for his friendship and overwhelming support while

being in the Ph.D. program together. I would like to give a special thanks to my family and friends, who supported me, and more importantly cheered me on over the last years to never give up on my dream of pursuing a Ph.D. In particular, I would like to mention Gail and Mike Yanney for their dedication and contributions to my success and career throughout the years. Finally, the most special "thank you” goes to Laurent Payan for his endless love and support and all the sacrifices he made. Without him and all of the people mentioned, it would have been impossible to reach my goal. 


\section{TABLE OF CONTENTS}

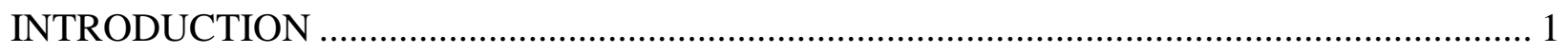

UNDERSTANDING ABUSIVE SUPERVISION: A REVIEW ……........................................... 4

Distinguishing Abusive Supervision From Other Similar Constructs ........................................... 4

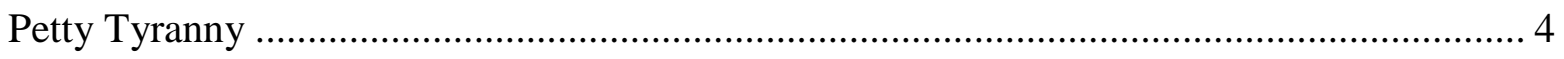

Workplace Aggression and Violence …………………..................................................... 5

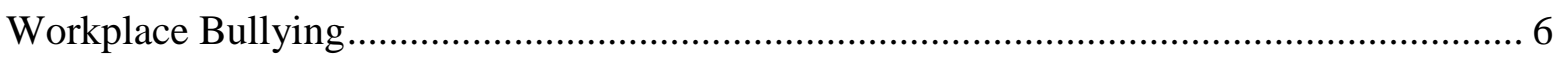

Supervisor Undermining.................................................................................................... 7

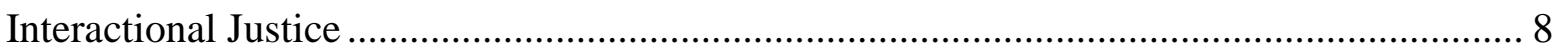

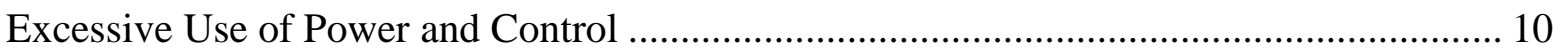

A Review of Abusive Supervision ........................................................................................... 12

Theoretical Foundations of Abusive Supervision ............................................................... 12

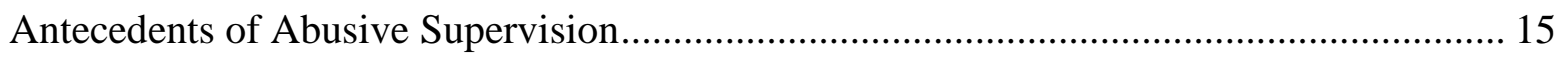

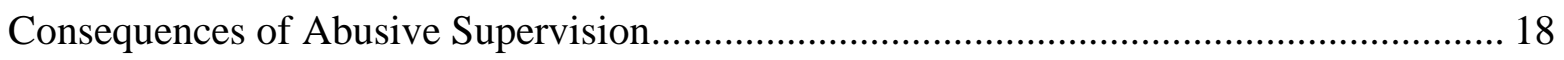

Recent Trends in the Literature ………........................................................................... 22

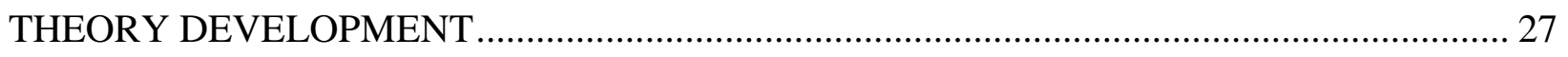

Observed Abuse and Third Party Reactions to Injustice.............................................................. 27

THE MODERATING EFFECTS OF INDIVIDUAL, RELATIONAL, AND

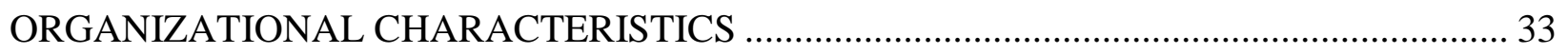

Individual Characteristics...................................................................................................... 33

Relational Characteristics................................................................................................ 36

Organizational Characteristics ………………………….................................................... 39

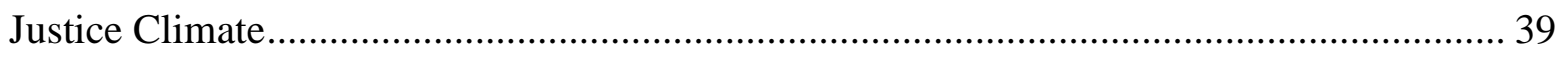


Organizational vs. Psychological Climate ................................................................ 40

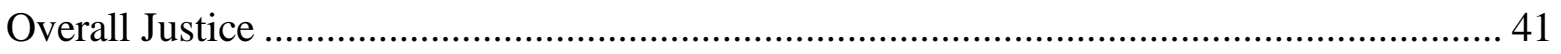

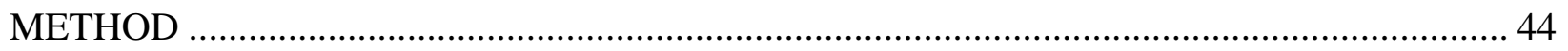

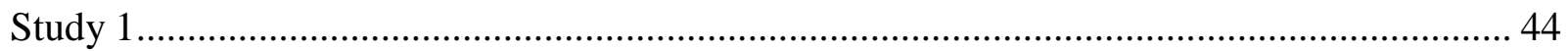

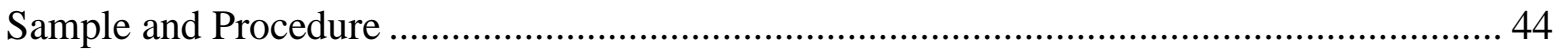

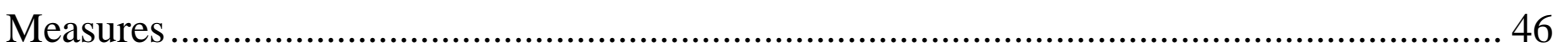

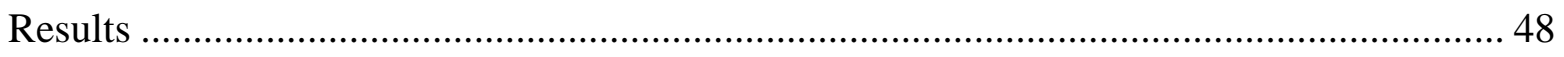

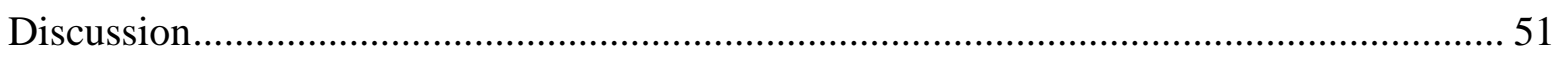

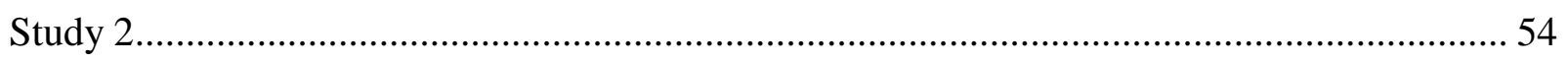

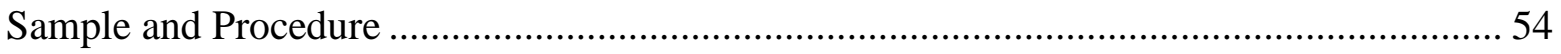

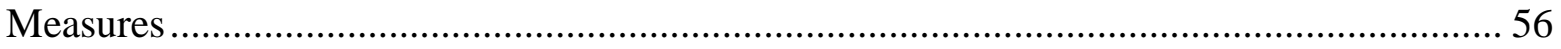

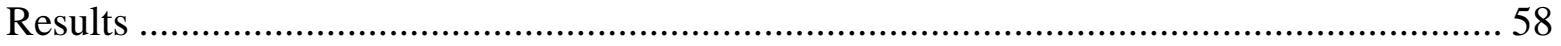

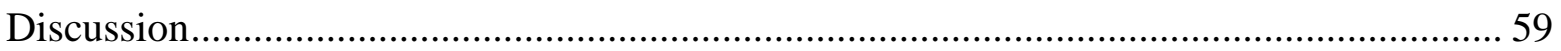

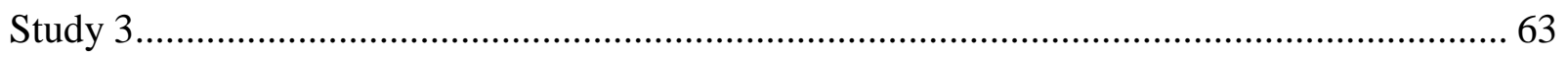

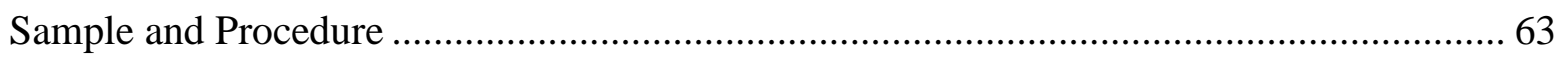

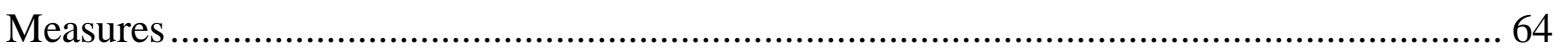

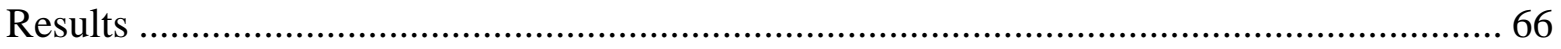

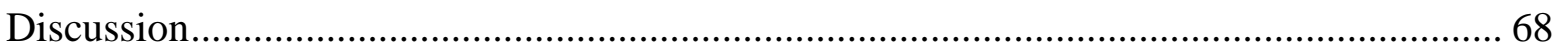

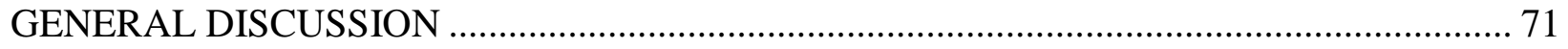

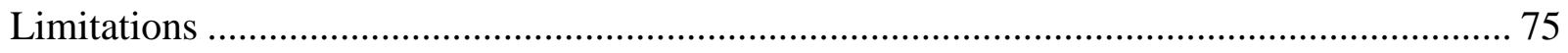

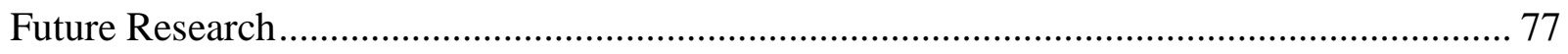

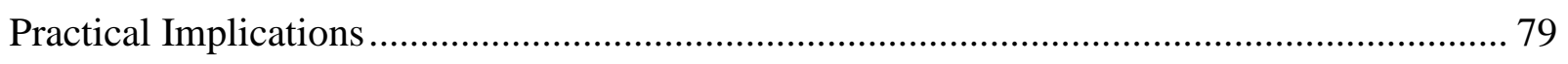

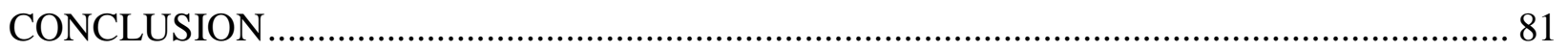




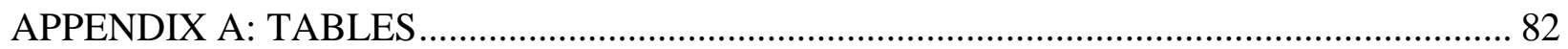

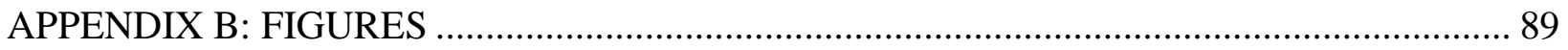

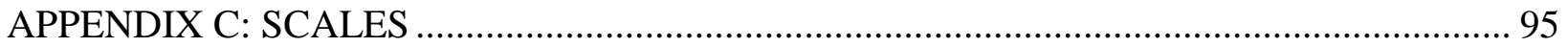

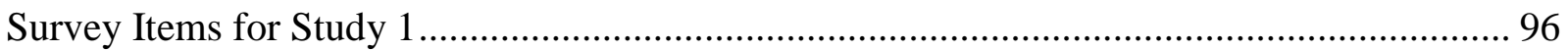

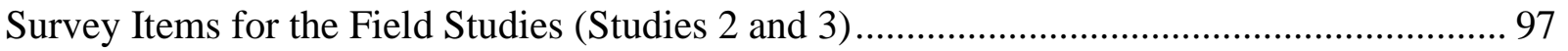

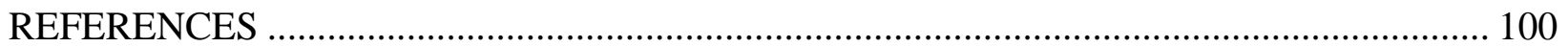




\section{LIST OF FIGURES}

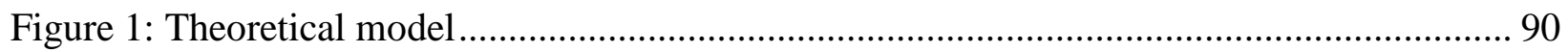

Figure 2: Study 1 Interaction between observed abusive supervision and friendship ties on

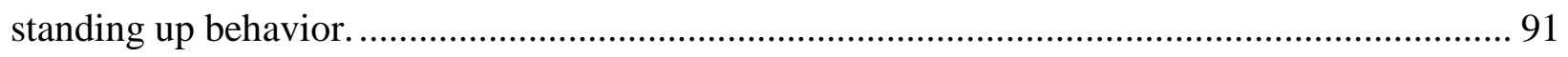

Figure 3: Study 2 Interaction between observed abusive supervision and friendship ties on standing up behavior............................................................................................................ 92

Figure 4: Study 3 Interaction between observed abusive supervision and organizational justice on

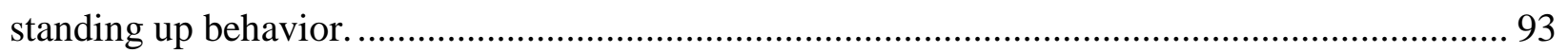

Figure 5: Study 3 Interaction between observed abusive supervision and organizational justice on

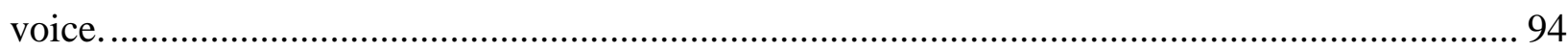




\section{LIST OF TABLES}

Table 1: Descriptive Statistics, Reliabilities, and Correlations of Study 1 Variables.................. 83

Table 2: Study 1 Results of Regression Analysis ................................................................. 84

Table 3: Descriptive Statistics, Reliabilities, and Correlations of Study 2 Variables.................. 85

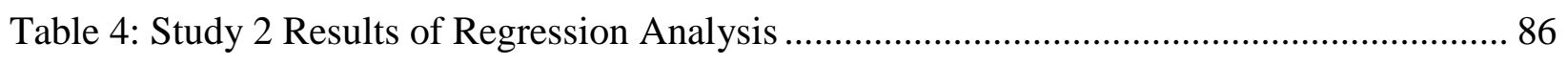

Table 5: Descriptive Statistics, Reliabilities, and Correlations of Study 3 Variables.................. 87

Table 6: Study 3 Results of Regression Analysis ............................................................ 88 


\section{INTRODUCTION}

The notion of abusive supervision has received substantial attention within the last decade. Abusive supervision is defined as “subordinates' perceptions of the extent to which their supervisors engage in the sustained display of hostile verbal and nonverbal behaviors, excluding physical contact” (Tepper, 2000, p.178). Compelling evidence points to a detrimental effect of abusive supervision on subordinates who are targets of the abuse. For example, abusive supervision has been linked to decreased work attitudes and increased health concerns in employees including job satisfaction, organizational commitment (Tepper, 2000), turnover intentions (Harvey, Stoner, Hochwarter, \& Kacmar, 2007), and employees’ somatic health issues (Bamberger \& Bacharach, 2006; Inness, Barling, \& Turner, 2005). Furthermore, abusive supervision has been associated with negative behavioral outcomes of employees including higher levels of subordinate aggression and deviance (e.g., Mitchell \& Ambrose, 2007; Thau \& Mitchell, 2010) and decreased organizational citizenship behavior (OCB) (Tepper, Hoobler, Duffy, \& Ensley, 2004; Zellars, Tepper, \& Duffy, 2002).

The first goal of this dissertation is to extend prior research on abuse in two ways. First, I examine the impact of abusive supervision from a different perspective than is typical in the literature. Rather than focusing on the target of the abuse and the negative impacts of abuse on that specific target, I investigate the effects of abusive supervision on third party observers who are not directly targeted. Second, I argue that observed abuse may be associated with prosocial behavior among employees, and that under distinct individual, relational, and organizational characteristics this relationship is strengthened. By examining positive reactions to observed 
abuse, I not only extend the abusive supervision literature, but also research on third party injustice (Folger, 1998, 2001).

The foundation for this research lies in deonance theory. According to deonance theory (Folger, 2001), observing the abuse of another person elicits moral unease and deontic reactions in people such as anger and moral outrage. These deontic reactions have been shown to initiate restorative justice behaviors in which the witness of injustice tends to punish the transgressor (e.g., O’Reilly \& Aquino, 2011; Skarlicki \& Rupp, 2010; Turillo, Folger, Lavelle, Umphress, \& Gee, 2002). Recently, research on deontic justice has also demonstrated that individuals who observe injustice find it more moral to not do anything at all (Rupp \& Bell, 2010), withdraw from the situation, or engage in constructive resistance (Greenbaum, Bardes, Mayer, \& Priesemuth, 2009, 2011). Drawing on research of Skitka’s (2002) value protection model and moral cleansing, another goal of this paper is to further extend this line of research and show that restorative justice behaviors may be of prosocial nature toward the victim of abuse.

In sum, this dissertation contributes to research on abusive supervision and third party injustice in several ways. First, I study abusive supervision in the eyes of an observer instead of focusing on the target of abuse. Second, I examine potential positive reactions to observed abusive supervision. This extends research on abusive supervision, as well as research on third party injustice, by showing that under some conditions observers of unfair treatment are prone to exhibit positive behavior to benefit the victim instead of punishing the transgressor or withdrawing from the situation. Finally, most research within the deontic justice literature has utilized experimental study designs in exploring research questions (see Greenbaum et al., 2009, 
2011, for an exception). This study further extends this research stream by generalizing the findings across one laboratory experiment and two field studies. 


\title{
UNDERSTANDING ABUSIVE SUPERVISION: A REVIEW
}

\author{
$\underline{\text { Distinguishing Abusive Supervision From Other Similar Constructs }}$
}

A number of constructs have emerged that resemble abusive supervisory behavior in the workplace. In this section, I identify some of these constructs and outline their similarities to and differences from abusive supervision.

\section{Petty Tyranny}

Petty tyranny is defined as a "manager’s use of power and authority oppressively, capriciously, and vindictively” (Ashforth, 1997, p. 126). Petty tyranny contains six subdimensions which include arbitrariness and self-aggrandizement, belittling subordinates, lack of consideration, a forcing style of conflict resolution, discouraging initiative, and noncontingent punishment.

Similar to abusive supervision, petty tyranny also involves superior wrongdoing towards subordinates (Tepper, 2007). However, in contrast with abusive supervision, petty tyranny examines behavior that may not necessarily be viewed as hostile at all times but can be regarded as being inconsiderate or unfriendly. This shows that the construct of petty tyranny seems more ambiguous in how employees' perceive the level of hostility and supervisor wrongdoing at times.

Research on petty tyranny has been limited. For example, Ashforth $(1997,2003)$ examined antecedents of this negative supervisory behavior. The author states that individual as well as situational factors influence petty tyranny. More specifically, Ashforth notes that an 
individual's preference towards dominance may be related to this destructive supervisory behavior. Moreover, organizational values or norms may also be associated with petty tyranny.

\section{Workplace Aggression and Violence}

Workplace aggression refers to individual behavior that is intended to harm others at work or the organization, whereas workplace violence is defined as a direct physical assault (Neuman \& Baron, 1998). Neuman and Baron distinguish between three types of aggressive behaviors which involve hostility (e.g., verbal aggression), obstructionism (e.g., actions designed to impede individuals to perform a job), and overt aggression (e.g., assault). On the other hand, Anderson and Bushman (2002) differentiate between hostile and instrumental aggression. The later notion refers to harming an individual to attain an ultimate goal.

When examining aggression and violence at the supervisory level, the construct captures similar content as abusive supervision, for example the frequency with which a supervisor yells at a subordinate. However, aggression does not exclude physical hostility between parties whereas Tepper (2000) specifically states that abusive supervision excludes physical contact.

Research on workplace aggression has examined antecedents (e.g., Dupre \& Barling, 2006) and consequences (Schat \& Kelloway, 2003). Some of the antecedents established are supervisor control (Dupre \& Barling, 2006), trait anger (Douglas \& Martinko, 2001), and situational and environmental factors including justice climate and community violence (Dietz, Robinson, Folger, Baron, \& Schulz, 2003). Other factors that influence workplace aggression and violence include interpersonal conflict and job satisfaction (Hershcovis Turner, Barling, Arnold, Dupre, Inness, LeBlanc, \& Sirvanathan, 2007). In contrast, Schat and Kellyway (2003) 
identify that workplace aggression has detrimental consequences to individuals such as somatic health concerns and a decrease in emotional well-being. In a recent meta-analysis, Hershcovis and Barling (2010) examined the impact of supervisor, coworker, and outsider (e.g., customer) aggression on three different attitudinal, behavioral, and health-related outcomes. Their findings show that supervisor aggression has the strongest effects on attitudinal and behavioral outcomes such as job satisfaction and workplace deviance, respectively. Interestingly, the researchers found no significant difference between the types of aggression on health related concerns.

\section{Workplace Bullying}

According to Zapf and Einarsen (2001, p. 369) workplace bullying occurs when an individual "persistently over a period of time, is on the receiving end of negative actions from one or several others, in a situation where the one at the receiving end may have difficulty defending him or herself against these actions.” In most cases of bullying, a powerful target abuses individuals with less power because it is more difficult for them to defend themselves. Hence, $75 \%$ of incidents within the workplace are perpetrated by superiors (Tepper, 2007). Similar to workplace aggression, the construct of bullying differs from abusive supervision as it does not only refer to destructive acts of a superior towards subordinates. Instead, bullying can be perpetrated by any organizational member (Hershcovis, 2011). However, similar to abusive supervision, bullying involves repeated exposure to hostile actions at work (Hoel, Rayner, \& Cooper, 1999).

Recent research on bullying shows that it leads to negative consequences such as posttraumatic stress disorder (Nielsen, Matthiesen, \& Einarsen, 2008), an increase in turnover 
intentions, or a decrease in job satisfaction (Rayner \& Keashly, 2005). In addition to consequences of bullying, recent studies also focus on antecedents of bullying. For example, Mathisen, Einarsen, and Mykletun (2011) found that a supervisor's personality characteristics (low contentiousness, high neuroticism) and exposure to stress fostered perceptions of bullying in the workplace. Finally, third party reactions to bullying have also been examined. Research shows that acts of bullying in the workplace not only negatively affect the target of these acts, but also the bystander (e.g., Einarsen \& Mikkelsen, 2003). Parzefall and Salin (2010) provide a theoretical model for these negative reactions and consequences on both parties. The authors argue that bullying behavior leads to perceptions of injustice and psychological contract breaches for both, the target of abuse and the bystander, which in turn cause negative consequences and reactions for the individuals.

\section{Supervisor Undermining}

Social undermining was first examined by Duffy, Ganster, and Pagon (2002) and is defined as "behavior intended to hinder, over time, the ability to establish and maintain positive interpersonal relationships, work-related success, and favorable reputation” (p. 332).

Overall, supervisor undermining is a construct that is closely related to that of abusive supervision. Like abusive supervision, supervisor undermining excludes physical hostility (Tepper, 2007). Moreover, Hershcovis (2011) states that both constructs show that the mistreatment stems from a person (supervisor) in a higher power position directed toward employees. Tepper suggests that items that measure undermining are similar to those of abusive supervision. However, it seems as if abusive supervision is a more direct or overt hostile 
behavior towards employees, whereas undermining can be done behind someone's back as some items of the supervisor undermining scale reveal (e.g., "Your supervisor spread rumors about you," "Your supervisor talks bad about you behind your back.”) Thus, in contrast with abusive supervision, supervisor undermining seems to be a more covert, hostile behavior that can hinder subordinates’ success or reputation at work.

Empirical work on supervisor undermining demonstrates affective, cognitive, and behavioral consequences, such as employee distress and counterproductive work behavior (Duffy et al., 2002; Duffy, Ganster, Shaw, Johnson, \& Pagon, 2006). Limited research has been done on the predictors of undermining. Duffy et al. (2006) suggest that group level undermining is related to individual level undermining via social learning or social information processing. The most recent research on undermining (Crossley, 2009) investigates the victim’s reactions to social undermining. More specifically, Crossley examines the underlying motives of the perpetrator and how these perceived motives influence a victim's reaction to the abusive behavior. Some reactions include revenge, avoidance, or reconciliation.

\section{Interactional Justice}

Interactional justice refers to the interpersonal treatment people receive from authorities and other members of the organization (see Colquitt, Conlon, Wesson, Porter, \& Ng, 2001). Moreover, interactional justice contains two components which refer to interpersonal justice and informational justice. Interpersonal justice reflects the degree to which people are treated with politeness, dignity, and respect by other members of the organization. Informational justice deals 
with explanations provided to people about why certain procedures were used and why outcomes were allocated in a certain way (e.g., Greenberg, 1990; 1993).

Tepper (2000) stated that interactional justice is a particularly important concept when examining abusive supervision. In essence, abusive supervision captures the negative interpersonal treatment of authority figures towards employees such that an abusive supervisor is rude and disrespectful toward a subordinate. This shows that both constructs are very similar because they deal with negative interpersonal treatment.

However, one distinction between justice and abusive supervision is that the notion of interpersonal justice can be experienced by employees as positive or negative. That is, people can receive fair or unfair treatment by others. In turn, the absence of abusive supervision may not trigger perceptions of fair treatment but create a neutral state instead. Furthermore, abusive supervision focuses on supervisors and their misdemeanor against subordinates only whereas interactional justice can also be present between coworkers or other parties besides supervisors and employees. In addition, looking at the interactional justice scale items (Colquitt, 2001), the construct captures a much broader dimension of interpersonal mistreatment. Some of the items refer to being treated with dignity and respect. Items of abusive supervision instead are narrower and focus on specific hostile behavior of a supervisor toward subordinates such as yelling at a subordinate or telling him or her that his or her feelings are stupid.

Interactional (in)justice has been associated with many positive as well as negative outcomes for employees. For example, Zapata-Phelan, Colquitt, Scott, and Livingston (2009) show that interpersonal justice influences task performance through employees’ intrinsic 
motivation. On the other hand, low interactional justice has been related to hostility and counterproductive work behavior (e.g., Jones, 2009; Judge, Ilies, \& Scott, 2006).

\section{Excessive Use of Power and Control}

Some more recent work within the realm of workplace deviance and supervisor aggression has examined concepts such as power or managerial control and its negative influence on subordinates. A wide array of leadership literature shows that power and control are valuable leader attributes necessary to influence followers (e.g., Rost, 1991). Moreover, control and power are established to guide employees to accepted behavior in the organization (e.g., Robinson \& Greenberg, 1998).

However, excessive use of power and managerial control may be detrimental for the supervisor-subordinate relationship. For example, Lawrence and Robinson (2007) show that power can be viewed in four different dimensions, which include influence (e.g., manipulation and negotiation), force (e.g., physical abuse), discipline (e.g., surveillance), or domination (e.g., discrimination). Perceiving power as a type of manipulation, discrimination, or abuse may influence deviant work behaviors of subordinates. Similarly, Detert, Treviño, Burris, and Andiappan (2007) argued that power predicted individuals’ perceptions of injustice and loss of autonomy, which triggers frustration and eventually leads to workplace deviance.

Dupre and Barling (2006) investigate the relationship between supervisor control and workplace aggression. The authors found that close supervisor control results in a feeling of constrained action and perceptions of interpersonal injustice which affect aggressive behavior. By the same token, Detert et al. (2007) examined managerial control and oversight as 
antecedents to subordinates' counterproductive work behavior in a restaurant setting. Counter productive work behaviors resulted in customer dissatisfaction due to angry servers or even food loss. Overall, these findings show that control and oversight are not always beneficial in preventing deviance; instead, these supervisor behaviors may harm employees, customers, and the organization.

Both constructs, excessive use of power and supervisor control, are similar to abusive supervision in that superiors trigger negative justice perceptions in subordinates which influence individuals to decrease their work attitudes and even engage in deviant behavior. However, both concepts are different from abusive supervision in that employee perceptions may be more ambiguous about the intent of hostile behavior. Some individuals may think that supervisors who monitor them closely or use certain influence tactics do not intend to cause negative justice perceptions within their employees. Instead, the supervisors may want to achieve the best outcomes for all parties involved. In contrast, abusive supervision, which reflects a hostile behavior from the supervisor toward an individual over a period of time, may create clearer perceptions of unfairness within subordinates. Another difference between excessive use of power or control might be the duration of the supervisor's behavior. As noted before, abusive supervision is a sustainable supervisor behavior toward a subordinate whereas research on power and control is silent about the time period the employee is exposed to these managerial actions.

In all, organizational scholars have provided many insights on abusive leadership behaviors. Each of these concepts is related to, yet conceptually distinct from abusive supervision. In particular, abusive supervision is a behavior directed only towards subordinates over a longer period of time. Furthermore, abusive supervision involves very specific negative 
behavior such as yelling at employees, but compared to other constructs excludes physical violence. In the next section, I will present a deeper description of the abusive supervision construct, review the relevant literature on antecedents and consequences, and discuss recent trends within the field.

\section{$\underline{\text { A Review of Abusive Supervision }}$}

As noted at the outset, abusive supervision refers to "subordinates' perceptions of the extent to which their supervisors engage in the sustained display of hostile verbal and nonverbal behaviors, excluding physical contact” (Tepper, 2000, p.178). Tepper states that the notion of abusive supervision evokes images of a tyrannical boss who publicly ridicules and undermines his or her subordinates. Furthermore, abusive supervision is a willful behavior and of repetitive nature.

\section{Theoretical Foundations of Abusive Supervision}

Research on abusive supervision has primarily drawn on three distinct literatures to understand the impact an abusive supervisor has on employees. First, social exchange theory (Blau, 1964) and its focus on norms of reciprocity explain employee engagement in deviant behavior in response to abusive supervision. Research found that subordinates reciprocate hostile behavior of their supervisors, or retaliate through deviant work behavior (Tepper, Duffy, \& Shaw, 2001; Thau, Bennett, Mitchell, \& Marrs 2009). Responses to abusive supervision based on social exchange and rules of reciprocity can come in a variety of forms, such that, at times individuals retaliate against the supervisor directly, the organizations, or other members of the organization. For example, Mitchell and Ambrose (2007) found that victims of abuse reciprocate 
abusive behavior by engaging in supervisor-directed deviance, or deviant behavior towards other members of the organizations. Tepper et al. (2001) instead demonstrated that individuals engage in resistant behavior at work.

A second type of theoretical rationale lies in the literature on aggression. Research on displaced aggression provides reasoning why supervisors or employees display abusive behavior (e.g., Aryee, Chen, Sun, \& Debrah, 2007). Displaced aggression refers to "redirecting harmdoing behavior from a primary to a secondary target” (Tedeschi \& Norman, 1985, p. 30). Hoobler and Brass (2006) found that employees, who perceived their supervisor to be abusive, were more prone to show abusive behavior towards their family. The authors further stated that displaced aggression is triggered by injustice and the main objective becomes to restore equity by creating unfair conditions for others. Mitchell and Ambrose (2007) argued that when being the target of abuse, employees release their frustration and aggression against a less powerful target, which increases organizational deviance, non-supervisor directed deviance, or family undermining (Hoobler \& Brass, 2006).

The third foundation of the abusive supervision literature comes from the field of organizational justice. In particular, Tepper (2000) proposed a justice based model of subordinates' responses to abusive supervision. In order to make fairness assessments in the workplace, individuals draw on perceptions of distributive, procedural, and interactional fairness. Tepper (2000) further suggests that abusive supervision is a source of interactional (in)justice (Bies \& Moag, 1986). Interactional justice possesses an interpersonal dimension of fairness (Bies, 2000), which includes being treated with respect, dignity, honesty, and sensitivity to one's personal needs (Bies \& Moag, 1986). A supervisor who shows interpersonal fairness provides 
important information to employees such as conveying they are highly valued members of the organization. However, if a supervisor engages in hostile or abusive behavior, this person may provide information suggesting distrust or incapability of an employee.

Drawing on justice theory, Tepper (2000) further argued that procedural justice and distributive justice matter in the fairness assessment of the supervisor and organization. More specifically, with respect to procedural justice, the author stated that an abusive supervisory behavior indicates that the organization has not done an adequate job of developing and enforcing fair policies and procedures that protect potential targets from abuse. Furthermore, witnessing or experiencing an abusive supervisor may result in a violation of the procedural justice principles stated by Leventhal (1980). For example, the ethicality rule would be violated if employees believe that the organization does not intervene and attempt to discipline the abuser.

When referring to distributive justice, Tepper (2000) argued that employees, who are targets of abuse, feel disadvantaged compared to others, not only because they are not treated equally, but also because they are not given the same resources from the supervisor. In addition, targets must overcome additional obstacles such as gaining information that the supervisor is unlikely to provide. Thus, extra time and effort must be put forth to fulfill all responsibilities.

Overall, employees form justice judgments about the organization and supervisors which refer to procedural, distributive, and interactional justice perceptions. As explained by prior research, an abusive supervisor influences all three justice perceptions of a subordinate, which can lead to detrimental consequences for the target, the supervisor, or the organization (e.g., Greenberg 1990, 1993). 
To summarize, the abusive supervision literature has primarily drawn upon three different theoretical perspectives for understanding employee reactions to abuse. These include social exchange theory, displaced aggression, and aspects of justice theory. Next, I will review the antecedents and consequences of abusive supervision that have been explored in the literature.

\section{Antecedents of Abusive Supervision}

Research of abusive supervision has focused on the development of the construct and its effects on employees' attitudes and behaviors. Only a limited amount of research actually examines predictors of abusive supervision. Below, I will describe studies that have investigated potential reasons that cause employees to view their supervisor as abusive. Research on antecedents has primarily drawn on the displaced aggression research and the justice literature.

First, Hoobler and Brass (2006) have examined the relationship between psychological contract breach of a supervisor and perceptions of abusive supervision. The authors describe that when a supervisor feels that his/her psychological contract has been breached, the supervisor experiences feelings of betrayal toward the organization and frustration. Drawing on the displaced aggression rationale, the individual who encountered a breach of his or her psychological contract is more likely to turn to a less powerful target (e.g., employees) to relieve the stored aggression. The authors conclude that a psychological contract breach is related to abusive supervision.

Aryee et al. (2007) suggested that a supervisor's perceptions of injustice may be related to employees’ perceptions of abusive supervision. Similar to Hoobler and Brass (2006), the authors stated that perceptions of injustice prompt a supervisor to release his/her negative 
feelings and anger towards other members (employees) in the organizations. Aryee et al. did not find a significant relationship between perceived injustice and perceptions of abusive supervision. Instead, they found a significant relationship between authoritarian leadership style and abusive supervision. An authoritarian leadership style is characterized as a disposition to enforce structure and rules. In addition, punishment systems for disobedience are in place. Overall, this type of leadership stresses personal dominance over subordinates which can influence employees’ perceptions of abusive supervision.

Tepper, Duffy, Henle, and Lambert (2006) also examined antecedents of abusive supervision. In contrast to Hoobler and Brass (2006) and Aryee et al. (2007), Tepper et al. draw on the depression literature as underlying rationale to examine precursors of abusive supervision. More specifically, the authors found that negative perceptions of procedural justice are related to depression which in turn triggers perceptions of abusive supervision. For instance, getting denied voice in decision making processes can decrease one’s self efficacy which results in depression. According to the authors, depressed people express their anger outwardly in order to regain a sense of control (Allen \& Greenberger, 1980). This would indicate that depression is associated with abusive supervision.

Recent research on antecedents of abusive supervision focused on the perceptions of victims and how specifically perceptions about an individual's core self-evaluations can lead to stronger perceptions of abusive supervision (Wu \& Hu 2009). Wu and Hu draw on the core selfevaluation literature to suggest that people with positive self-evaluations are prone to seek out positive perceptions about their workplace to create a fit between the self-concept and environment. In contrast, $\mathrm{Wu}$ and $\mathrm{Hu}$ further argued that employees with low core self- 
evaluations are more drawn to negative aspects which may create stronger perceptions of the destructive leadership behavior. The author found support for their assertions.

Another recent study on the antecedents of abusive supervision was published by Restubog, Scott, and Zagenczyk (2011). The authors examine the effect of aggressive norms in the work environment on abusive supervision. If aggressive norms are present in the workplace, employees tend to model and adapt these negative norms which can foster abusive behavior in organizations. Restubog and colleagues found support for the effect of contextual factors on abusive supervision.

In sum, there has been limited, yet growing research on antecedents of abusive supervision. The papers described here examine organizational unfairness, authoritarian leadership style, psychological contract breach, contextual factors, or specific characteristics about the victim as antecedents of abusive supervision. Below I will describe some of the moderating effects of these studied relationships.

\section{Moderating Effects of the Relationship Between Antecedents and Abusive Supervision}

The focus on the victim of abuse remains when researchers shifted their interest to investigating contextual and dispositional factors that may moderate the relationship between antecedent variables and abusive supervision. More specifically, supervisory and subordinate characteristics have received increased attention as moderating variables. For example, Tepper et al. (2006) examined the concept of victim precipitation, which refers to the idea that some individuals are more prone than others to be the victim of abuse. The authors found that people who are high on negative affectivity were more likely to get abused by a supervisor. Individuals high on negative affectivity (NA) are generally anxious, insecure, fearful, and sad. Hence, they 
may face more distress than others which can lead to performance issues. Once performance issues occur, supervisors are more likely to target these individuals. Tepper et al. conclude that individuals high on NA are more vulnerable to aggressive behavior by the supervisor.

Hoobler and Brass (2006) investigated potential moderating conditions of the relationship between psychological contract violations of the supervisor and abusive behavior. The authors examined whether a supervisor's hostile attribution bias would moderate the relationship. Hostile attribution bias refers to an individual's tendency to interpret actions of others as hostile towards themselves. These people blame others for their misery and problems, and develop an extra punitive mentality (Hobbler \& Brass, 2006). The authors further argue that people with a hostile attribution bias blame the situation for their lack of success and hence violate those around them. Hooble and Brass found support for the moderating effect of possessing a hostile attribution bias.

In conclusion, scholars focus on characteristics of the victim and supervisor dispositions as moderating effects between antecedents and abusive supervision. Research on victim precipitation and supervisor dispositions provide further insights into the relationships studied.

\section{Consequences of Abusive Supervision}

Over the past ten years, much research has focused on the consequences of abusive supervision. In his review of the abusive supervision construct and literature, Tepper (2007) stated that scholars examined different consequences including work-related attitudes, deviant work behavior, and psychological distress. For example, in the first empirical article about abusive supervision, Tepper (2000) found that abusive supervision is negatively related to work attitudes such as job satisfaction and commitment. In addition, he found a positive relationship 
between abusive supervision and work-family conflict and psychological distress. Similar results were found by Tepper et al. (2004), Tepper and Lockhart (2005), and Hobman, Restobug, Bordia, and Tang (2009). Zellars et al. (2002) instead showed that abusive supervision is negatively related to a decrease in organizational citizenship behaviors (OCB) whereas Harris, Kacmar, and Zivnuska (2007) showed that abusive supervision negatively impacts job performance.

Recent work on abusive supervision has increased its focus on retaliation and deviant work behaviors of the targets (Biron, 2010; Thau \& Mitchell, 2010; Tepper, Carr, Breaux, Geider, Hu, \& Hua, 2009). Mitchell and Ambrose (2007) showed that abusive supervision predicted different kinds of workplace deviance. More specifically, the authors found that abusive supervision is associated with supervisor-directed deviance. Mitchell and Ambrose categorize abusive supervision as a type of aggression and interpersonal mistreatment. In order to make the wrongdoer pay for his or her actions, the targets retaliated against the source of injustice. Additionally, the authors demonstrated that abusive supervision was also related to organizational and non-supervisor interpersonal deviance.

Thau et al. (2009) also focus on employee reactance when encountering an abusive supervisor. Consistent with research by Mitchell and Ambrose, the authors found that abusive supervision is related to interpersonal and organizational deviance. Moreover, Thau et al. found that the relationship between having an abusive supervisor and workplace deviance is contingent upon conditions of high uncertainty. Drawing on uncertainty management theory (Lind \& Van den Bos, 2002; Van den Bos \& Lind, 2002), the authors state that individuals’ focus on fairness is stronger under conditions of high uncertainty. Hence, perceptions of fairness and an abusive 
supervisor seem more salient in times of uncertainty, which strengthens the relationship between abusive supervision and deviance, in particular, supervisor-directed deviance.

Overall, abusive supervision has been related to many outcomes that are relevant to individuals, relationships, and the organization. Most abusive supervision research has focused on its impact on negative outcomes for individuals including deviant acts in the workplace (Mitchell \& Ambrose, 2007; Thau et al., 2009), emotional exhaustion (Grandey, Kern, \& Frone, 2007; Wu \& Hu, 2009) or alcohol abuse (Bamberger \& Bacharach, 2006). However, especially these most recent papers reveal an emerging trend within the abusive supervision literature. That is, researchers are more and more intrigued by identifying conditions under which the effect of abuse on outcomes is stronger or weaker. Below, I will elaborate on this recent trend as well as some other novel directions in the literature.

\section{Moderating Effects of the Relationship Between Abusive Supervision and Outcomes}

Recent papers investigate individual processes or contextual variables as potential moderators of the relationship between abusive supervision and negative outcomes for the target of abuse and/or organizations. For example, Harvey et al. (2007) found that positive affect neutralized the combined effects of abusive supervision and ingratiation techniques on job tension, emotional exhaustion, and turnover intensions. These findings reveal that people who are generally more positive are able to redirect their resources toward positive behavior and emotions which mitigates the negative effect of abuse on employee consequences. This study was among the first to examine neutralizing effects of abuse on important employee outcomes.

Other research has focused on the conditions which increase employees’ negative reactions to abusive supervisory behavior. Specifically, some contextual factors have shown to 
be relevant when considering how strongly abuse can impact employees. For example, Tepper, Henle, Lambert, Giacalone, and Duffy (2008) examined the relationship between abusive supervision and workplace deviance, and found that group norms moderate the relationship, such that if coworkers display similar behaviors, or if a certain behavior is accepted within the group, the relationship between abusive supervision and deviant behavior is stronger.

Aryee, Sun, Chen, and Debrah (2008) found that organizational structure strengthened the positive relationship between abusive supervision and performance assessments such as job dedication. The authors showed that in a mechanistic structure, the relationship between abusive supervision and employee outcomes is stronger because stricter supervision and therefore, greater opportunity for abusive supervision is increasingly provided in a mechanistic structure, compared to an organic one, in which employees possess autonomy and have fewer interactions with superiors.

Another contextual factor that seems to moderate the impact abuse has on employee outcomes is perceptions of leadership style within the work environment. As noted above, Thau et al. (2009) demonstrated that different leadership styles in the work environment impacted the relationship between abuse and workplace deviance. Yet another study by Thau and Mitchell (2010) examines the moderating condition of distributive justice on the relationship between abusive supervision and workplace deviance. The authors revealed that the confusion of experiencing distributive justice, while also being the target of abuse, strengthens the impact abusive supervision has on negative employee behavior.

Finally, Tepper et al. (2009) focused on individual attitudes, and how those can affect the influence of abusive supervision. The authors showed that turnover intentions moderated the 
relationship between abusive supervision and workplace deviance such that the relationship was stronger when people had intentions to exit the organizations. Also emphasizing the relevance of job perceptions and attitudes, Harris et al. (2007) found that individuals’ perceptions about the work itself influenced the relationship between abusive supervision and job performance.

To summarize, scholars have recently been interested in investigating the conditions under which the effects of abusive supervision on employee outcomes are stronger or weaker. Research found that contextual factors such as different leadership styles or an organization’s structure influence abusive relationships. Furthermore, characteristics of the target also influence the relationship between abusive supervision and outcomes. However, besides examining the moderating effects that inform research on abusive supervision, some other trends can be also identified in the literature. These trends will be described in the next section.

\section{Recent Trends in the Literature}

Why Do Supervisors Engage in Abusive Supervision?

Most recent research by Tepper, Moss, and Duffy (2011) focuses on providing explanations for why supervisors may act in an abusive manner toward employees. Tepper and colleagues focus on moral exclusion theory and find that deep-level dissimilarity between the supervisor and employee, relational conflict between the two parties, and low performance of subordinates encourage the supervisor to exclude this individual, and also to withdraw any fair behavior toward this person. The result is abusive behavior from the supervisor toward the employee. Previous research on antecedents of abuse supervisory behavior has primarily looked at supervisor's negative experiences in the workplace which translated into aggressive behavior toward employees. This research by Tepper et al. contributes to the narrow stream of antecedents 
of abusive supervision by introducing novel theoretical rationale, and providing empirical findings in a time lagged manner that explain why supervisors engage in abusive behavior without having been the target of unfair treatment themselves, or having aggressive personalities.

\section{Integrating More Theoretical Foundations}

Another trend in the literature focuses on enriching the research on abusive supervision by integrating different theoretical rationales. For example, Tepper et al. (2008) introduced theoretical rationale to the realm of research by showing that affective commitment of the target mediates the relationship between abusive supervision and workplace deviance. More specifically, they stated that individuals who experience abuse blame the organizations for tolerating this questionable behavior. This conflict with the organization will decrease the commitment an employee has built. This decrease in commitment elicits deviant behavior of subordinates.

Scholars who focus on conditions under which the effect of abuse is stronger or weaker draw on many different theoretical foundations that accompany those of abusive supervision. For example, Harris et al. (2007) integrate social exchange theory (Blau, 1964) and conservation of resources theory (COR) (Hobfoll, 1989) when showing that job characteristics moderate the relationship between abuse and performance. The authors suggest that abusive supervision not only prompts employees to retaliate, but also depletes individual resources such as time spent on the job which negatively affects peoples’ performance. Similarly, Tepper et al. (2009) integrate research from social exchange theory and power dependency theory (Emerson, 1972), and argue employees are more prone to display deviant behavior when they feel they are less dependent on their supervisor and organization. This lack of dependency is assessed by individual's intentions 
to leave the organization. Further, research by Thau et al. (2009) conjoins social exchange theory and uncertainty management theory (Lind \& Van den Bos, 2002). Employees perceive a leadership style that is more authoritarian as more structured, strict, and inflexible which leaves little room for uncertainty in the work environment. One the other hand, a work place that is characterized by a low authoritarian style fosters uncertainty within individuals. According to uncertainty management theory, justice perceptions become more important and salient in times of uncertainty which enhances the effect an abusive supervisor has on employee deviant behavior.

Thau and Mitchell (2010) draw on competing theoretical rationales when investigating the interaction effect of abusive supervision and distributive justice on deviant work behavior. The authors propose that research on self-gain and self-impairment provide opposite reasoning for why distributive justice can either strengthen or weaken the impact abuse has on deviance. Thau and Mitchell found support for the self-regulation impairment rationale which states that abusive behavior from the supervisor drains self-resources from the individual. Under conditions of high distributive justice, inconsistent information is received by the individual, which further depletes self-resources and thus strengthens the positive relationship between abusive supervision and workplace deviance.

Finally, Restubog et al. (2011) extend the abusive supervision literature by drawing on transactional theory of stress (Lazarus \& Folkman, 1984) when studying the top-down effect of abusive supervision on psychological distress and spouse undermining. The authors argue that abusive supervision represents a stressor to the subordinate, and is associated with many negative feelings, fears, anxiety, and depression. Individuals who experience fear-based anxiety feel 
distressed and tend to use emotion-focused coping which translates into venting or blowing off steam as well as spouse undermining.

\section{$\underline{\text { Abusive Supervision and Positive Outcomes }}$}

Another trend in the literature can be identified when analyzing the breadth of outcome variables that have been examined in the abusive supervision literature. Even though most abusive supervision research emphasizes the negative impacts of this destructive supervisory behavior, indeed some research has also considered different employee responses to abuse such as upward communication, voice, and OCB. Tepper et al. (2001) were among the first to examine employees' engagement in constructive resistance, referred to as open communication between the abusive supervisor and the employee about the negative events. Constructive resistance may improve the relationship between the supervisor and employee. Findings show that individuals high on agreeableness and low on conscientiousness are more prone to engage in constructive resistance and attempt to improve the relationship between the supervisor and employee. Yagil (2006) also explored upward influence tactics as reactions to abusive supervision. The author found that abusive supervision led to forceful influence tactics used by employees. Forceful influence tactics are those in which an employee tries to block the supervisor and his/her decisions by limiting communication and coordination with the superior. Recently, Burris, Detert, and Chiaburu (2008) examined how abusive supervision impacts employee voice behavior directed toward the supervisor. Burris and colleagues found that organizational detachment mediated the negative relationship between abusive supervision and voice behavior. 
To conclude, recent trends in the literature focus on the motives supervisors possess to exhibit abusive behavior. Furthermore, scholars have enriched the abusive supervision literature by integrating different theoretical rationales and diverse outcome variables (e.g., positive reactions). I intend to follow and add to these recent trends by examining third party reactions to abuse and potential positive employee responses. Therefore, besides shifting the focus to the observer and his/her reactions, I integrate different literatures and theories into the abusive supervision research. In addition, I add to the research by examining prosocial reactions to abusive supervision. Below, I will delve deeper into my theory and hypotheses development. 


\section{THEORY DEVELOPMENT}

As noted, with this dissertation I extend the search for other possible constructive, positive, and upward communicative outcomes. Specifically, I explore the outcome variables of helping, voice, and standing up behavior. In contrast to most previous research, I will focus on the positive effect abusive supervision may have on employees. I further extend the literature by focusing on prosocial responses of those who observe- but are not targets of — abusive supervision. In the next section, I focus on understanding the process by which observing abuse might lead to prosocial behavior.

\section{Observed Abuse and Third Party Reactions to Injustice}

Skarlicki and Kulik (2005) stated that supervisor abuse invokes strong moral emotions in observers which drive people to act. Thus, recently, justice and abuse researchers have expressed an interest in examining third party reactions to mistreatment at work. In particular, the justice research provides insights about how third parties — those not directly the target of injusticereact to unfair treatment (e.g., Rupp \& Bell, 2010; Skarlicki \& Kulik, 2005). Most of this research points to retributive reactions of the observer (Kahneman, Knetsch, \& Thaler, 1986; Niehoff, Paul, \& Bunch, 1998; O’Reilly \& Aquino, 2011; Skarlicki \& Rupp, 2010). For example Turillo et al. (2002) were among the first to conduct a series of laboratory experiments and found that people responded negatively when they observed unfair treatment from one party to another. Their study showed that individuals were willing to sacrifice their own good (monetary value) in order to punish the transgressor. The tendency for individuals to respond to unfair treatment in 
negative ways has been replicated in a recent field study. Greenbaum et al. (2009) found that employees are more likely to become deviant after witnessing third party abuse of customers.

One potential explanation for these findings lies in deonance theory (Folger, 2001). Deonance theory argues that witnesses to injustice are motivated to restore justice. That motivation primarily focuses on punishing the transgressor. Cropanzano, Goldman, and Folger (2003, 2005) suggested deontic justice deals with treating others as they deserve to be treated while upholding moral standards and ethically appropriate behavior. Moreover, Cropanzano et al. argued that people uphold moral norms or principles and once these get violated, individuals act upon their internalized moral sense of duty and are prone to penalize the transgressor.

Deontic justice is based on the Greek term “deon” which refers to obligation or duty and includes expressions such as should, must, or ought to. The philosopher Immanuel Kant described perfect and imperfect duties, in which perfect duties in particular provide a basis for deonance theory. Perfect duties can be explained as universal principles humans need to comply with and act according to. One example of a perfect duty is to treat people with respect and dignity. That is, people care about fair and respectful treatment because it is the right thing to do and an obligation for each person (Folger, 2001).

Following the deontic rationale, justice becomes a moral imperative. All people are required to uphold and abide by moral principles and social norms in society. Witnessing individuals deviating from these norms and principles invokes a moral response within the observer. Furthermore, people feel unease because the transgressor places him/herself above others in terms of morals and moral behavior. These strong moral responses of the third party can be described as deontic anger and moral outrage which are also referred to as deontic 
reactions. These emotions encourage the third party observer to restore justice which can be exhibited in punishment for the transgressor (e.g., Kahneman et al., 1986; Skarlicki \& Rupp, 2010; Turillo et al., 2002).

Even though most deontic justice research focuses on self-sacrifice and punishment of the perpetrator, recent research extends this line of thinking and examines other forms of restorative justice behavior. For example, Rupp and Bell (2010) found that some observers respond to injustice by not doing anything at all. The authors draw on moral self-regulatory processes that the observer of injustice experiences. Not engaging in punishment represents an ethical choice for the witness. Some people believe that all ethical motivation is to "not do any harm" to others. Therefore, when observing third party injustice, a moral dilemma opens up for the observer who believes acting in a negative way toward the supervisor is as unworthy as the transgression itself. As Rupp and Bell argue, the natural response when observing injustice is to engage in retributive behavior toward the transgressor, however the self-regulatory mechanisms represent a countermotivation in which not doing anything presents itself as a more moral solution. The selfregulatory mechanisms that act inside individuals consist of inhibitory or proactive processes which cause individuals to refrain from unethical actions and motivate people to do the right thing. Following Rupp and Bell’s rationale and findings, Greenbaum et al. (2009, 2011) show that individuals engage in withdrawal behavior depicted by an increase in turnover intentions. The authors further show that observers of abuse are also prone to engage in constructive resistance which includes doing the right thing by approaching the supervisor about his/her actions. 
In addition to punishing the perpetrator or withdrawing from actions entirely, individuals may also be prone to show prosocial behavior to benefit the victim of abuse. Two sets of literatures suggest that observing abusive supervision may motivate people to engage in prosocial behavior. The first involves research on the value protection model and its focus on moral mandates (Skitka, 2002; Skitka \& Mullen, 2002) and moral cleansing. The second type is research on guilt.

Moral mandates are strong attitudes and values that are central to a person’s identity (Skitka, 2002). Examples of moral mandates are the enforcement of freedom, life, or the right to equality. Moral mandates represent a major component of the value protection model (VPM; Skitka, 2002) which states that when personal moral values are threatened, individuals are inclined to express and protect their values and identity. According to Skitka and Mullen (2002) moral mandates are violated by thinking about, experiencing, or witnessing a transgression, or by behaving in an unethical manner. This indicates that, similar to deontic principles, moral mandates can be violated when a third party observes a transgression done to another person. When experiencing a violation of moral mandates, people are morally outraged and are motivated to alleviate the incongruence between their morals and the present violation by engaging in cognitive, affective, and/or behavioral adjustments that reinforce their sense and identity of being a good person.

The literature on moral cleansing provides insights about the type of behavioral responses individuals exhibit after experiencing a violation of their moral mandates. Moral cleansing refers to the behavior individuals engage in to reaffirm their sense of being a good person. Moral cleansing behaviors range from simply washing or cleaning one’s hands (Schnall, Benton, \& 
Harvey, 2008; Zhong \& Liljenquist, 2006) to prosocial behavior such as human rights activism, working to protect the environment, donating blood, or engaging in silent marches for victims of abuse (Lodewijkx, Kersten, \& Van Zomeren, 2008; Skitka \& Mullen, 2002). It is these prosocial behaviors toward the victims that are of interest in my dissertation.

Drawing on research of the VPM, moral mandates, and moral cleaning, studies show that individuals do demonstrate prosocial behavior after witnessing harm or injustice done to others and experiencing a violation of their moral selves. Abusive supervision represents a severe case of injustice in which the supervisor mistreats employees and disrespects them. Therefore, witnessing abusive supervision may present a violation to someone’s moral mandates. To alleviate a threat to one's values and identity, the person engages in prosocial moral cleansing behavior to remind the self and others that he/she is a good person and to maintain a positive self-identity.

Another type of literature that suggests people exhibit prosocial behavior after witnessing harm done to others is research on guilt. Guilt has many different facets. For example, individuals can experience guilt based on a transgression they took part in, but also when they have gained an accidental advantage over another person (O’Connor, Berry, Weiss, Bush \& Sampson, 1997). Much research refers to this second type of guilt as survivor guilt. Research further finds that when people experience survivor guilt they attempt to alleviate this guilt by engaging in prosocial behavior towards others (see Baumeister, Stillwell, \& Heatherton, 1994, for a review). Folger and Cropanzano (2010) related the notion of survivor guilt to perfect and imperfect duties. The authors describe how observers, who witness a violation of imperfect duties towards others, experience guilt because they are better off and in a better position than 
those people. Equity theory (Adams, 1965) and research on guilt suggest that people are inclined to reduce their distress by engaging in opportunities to help others. Research shows empirical support for these assertions. For example, Wayment (2004) and Wayment, Silver, and Kemeny (1995) found that individuals experiencing survivor guilt after a tragedy engaged in helping behavior and showed support for victims. Finally, Rawlings (1968) found that observers of harm showed the same amount of prosocial behavior as people who felt guilty after engaging in harm doing.

In all, both theoretical and empirical research from the VPM and the guilt literature point to prosocial reactions on the part of individuals who witness abusive supervision. Thus, I suggest the following hypothesis.

Hypothesis 1: Observed abusive supervision is positively related to prosocial reactions of the observer aimed at benefitting the victim of abuse. 


\section{THE MODERATING EFFECTS OF INDIVIDUAL, RELATIONAL, AND ORGANIZATIONAL CHARACTERISTICS}

Hypothesis 1 describes the positive relationship between observed abusive supervision

and prosocial reactions of the observer aimed at benefitting the victim. However, the strength of this relationship might vary depending on a variety of factors. The reactions of the witness of abuse might be influenced by individual characteristics, how the witness perceives the relationship with the target of abuse (relational characteristics), or how the witness views the organizational setting in which the abuse of the coworker is taking place (organizational characteristics). The following sections address these moderators, which include moral courage, friendship ties between the victim and the observer of abuse, and overall justice climate.

\section{$\underline{\text { Individual Characteristics }}$}

The strength of reactions by the witness of abusive supervision may depend on characteristics of that individual. Here I focus on the observer's moral courage which may moderate the relationship between observed abusive supervision and prosocial reactions. Moral courage has its foundations in the more general concept of courage, which has been investigated as part of human nature for thousands of years. During ancient times, courage was primarily examined in military or battlefield settings. When describing courage, philosophers such as Aristotle and Socrates termed courageous people as those who are willing to remain at their post and defend themselves against the enemy without running away (see Miller, 2005).

This attribute of facing fear has dominated some of the courage literature in ancient as well as in modern times. Miller (2005) cites Aristotle who explained a man encounters many 
fearful things in life including death. Aristotle concluded that if a man can face the fear of death and die on the battlefield, he earns the distinction of dying with courage. More recent research proposes that courage "reflects the state or quality of mind or spirit that enables someone to face danger, fear or vicissitudes with self-possession, confidence and resolution” (Sekerka \& Bagozzi, 2007, p. 135). Sekerka and Bagozzi further state that courage represents strength of character which aids individuals to exhibit acts of bravery and the willingness to overcome or endure threats to oneself in pursuit of the right action.

Scholars distinguish between acts of physical courage (e.g., deeds in the battle, extreme athletes, firefighters, police officers; Miller, 2005) and moral courage (e.g., Jubb, 1999; Kidder \& Bracy, 2001, Sekerka \& Bagozzi, 2007). Moral courage has been exemplified by individuals including Martin Luther King, Jr., who stood up to enforce equal rights for African Americans. Moreover, we are familiar with stories of German, Polish, and Dutch families who hid Jews in Nazi-occupied Europe to save and protect people from the Holocaust. Kidder and Bracy (2001) use the term righteous human beings when describing these individuals who demonstrate acts of moral courage.

Even though we have recollections of many individuals displaying moral courage, a specific definition of moral courage has been elusive in the ethics literature. For example, Kidder and Bracy (2001) refer to moral courage as the "quality of mind and spirit that enables one to face up to ethical dilemmas and moral wrong doings firmly and confidently, without flinching or retreating” (p.5). Sekerka and Bagozzi (2007) define moral courage as the ability to use inner principles to do what is good for others, regardless of a threat to self, as a matter of practice (p. 135). Drawing on acts of moral courage in the workplace, Sekerka, Bagozzi, and Charnigo 
(2009) investigate the construct of professional moral courage which they define as an attribute that enables individuals to take the right course of action, given the ethics of their profession (p. 566). In this dissertation, I will draw on Sekerka and Bagozzi’s (2007) definition and refer to moral courage as the ability to use ethical principles to do what is good, regardless of a threat to self.

Research on moral courage in organizations has been very limited even though, recently, scholars have expressed an increasing interest in the phenomenon. Moral courage is reflected in the acts of individuals that practice the right behavior based on ethical or moral principles regardless of any risk. As noted above, people like Martin Luther King, Jr. are great examples of people who follow their moral principles and show the right behavior regardless of a threat to themselves. In a workplace setting, we find people like Cynthia Cooper or Sherron Watkins who decided to "blow the whistle" when their employers (WorldCom and Enron, respectively) were engaging in fraudulent behaviors. Because whistleblowers in organizations face tremendous consequences and threats such as humiliation, ridicule, loss of social standing, and unemployment (Kidder \& Bracy, 2001), people engaging in these moral behaviors are thought to be equipped with higher levels of moral courage (Grant, 2002; Judd, 1999). Grant goes so far as referring to whistle blowers as "saints of a secular culture" as these employees self-sacrifice for what is morally right.

Integrating research on moral courage and third party injustice, Hypothesis 1 suggests that observers will respond to abusive supervision by engaging in prosocial acts aimed at benefitting the victim of abuse. However, those who perform benefitting acts toward the coworker engage in a risky endeavor. Supervisors present a higher power in organizations and 
control important resources for employees. Furthermore, some abusive supervision and aggression research states that individuals may divert their frustration into deviant and aggressive behavior towards others, because the risk of future punishment and further retaliation from the supervisor is too daunting (Hoobler \& Brass, 2006; Miller, 1941; Mitchell \& Ambrose, 2007; Restubog et al., 2011). Therefore, to overcome these potentially risky and negative consequences, higher levels of moral courage on part of the observer may result in greater prosocial behavior after witnessing abuse. In other words, individuals with higher levels of moral courage will be less dissuaded by the potential risk that accompanies aiding the victim of abuse. Thus, I posit the following hypothesis.

Hypothesis 2: Moral courage moderates the relationship between observed abusive supervision and prosocial reactions such that the relationship will be stronger when moral courage is higher.

\section{$\underline{\text { Relational Characteristics }}$}

In addition to individual characteristics of the observer, I suggest that relational aspects between the witness of abuse and the victim can also influence the strength of the relationship between observed abusive supervision and prosocial behavior. Specifically, whether the observer perceives close personal ties (friendship) with the victim may provide insights about the strengths of prosocial reactions to witnessing supervisory abuse. Some evidence within the bystander literature and research on altruism and helping point to the fact that mistreatment of people close to oneself elicits prosocial reactions in observers (e.g., D’Cruz \& Noronha, 2010; Schlenker \& Britt, 2001). The reason why friends or people with close personal ties demonstrate 
prosocial behavior after observing harm is grounded in the notion of oneness (Cialdini, Brown, Lewis, Luce, \& Neuberg, 1997) and social identity (Tajfel \& Turner, 1986).

According to Cialdini et al. (1997), oneness refers to a "sense of shared, merged, or interconnected personal identities” (p.483). In other words, when people experience a sense of oneness, they find more of themselves in the other person and feel closely related to this individual. Friendship ties, familiarity, or kinship are particularly likely to reveal attachment related cues between individuals which will strengthen perceptions of oneness. Research shows that individuals are more inclined to aid a person in need when they perceive attachment or oneness toward this person (e.g., Cialdini et al., 1997; Maner, Luce, Neuberg, Cialdini, Brown, \& Sagarin, 2002; Neuberg, Cialdini, Brown, Luce, Sagarin, \& Lewis, 1997). For example, Cialdini et al. (1997) showed that greater helping behavior was observed when participants were told that the person in need was a family member or a friend compared to an acquaintance or a stranger.

A notion similar to that of oneness is social categorization (Hogg \& Terry, 2000) which describes that people categorize themselves as part of ingroups based on similarity and attraction between members (Hogg \& Terry, 2000). Friends, or people with close personal ties share interpersonal attraction (Hogg, 1987), frequent communication, cohesion, trust, and solidarity (Gulati, Dialdin, \& Wang, 2002). Therefore, people with friendship ties categorize themselves are part of an ingroup indicating a strong social identity or "we” feeling (Hogg \& Hains, 1998). This "we" feeling in turn leads to stronger feelings of closeness and also increased concern for the welfare of others in the group (Levine, Prosser, Evans, \& Reicher, 2005). Empirical research supports the fact that greater identification influences prosocial behavior after observing 
unfortunate events harming others (Simon, Stürmer, \& Steffens, 2000; Stürmer, Snyder, Kropp, Siem, 2006). For example, Stürmer, Snyder, and Omoto (2005) showed that people were more prone to engage in helping behavior toward other members of their ingroup. In a similar vein, research from the bystander literature emphasizes the importance of close ties and a common identity. Studies show that observers were more inclined to help the victim when they knew the person or perceived similarity between themselves and the victim (Levine, Cassidy, Brazier, \& Reicher, 2002; Levine \& Crowther, 2008; Kogut \& Ritov, 2007).

Following research from the notion of oneness and social identity, I suggest that friendship ties between the observer of abuse and the victim may moderate the relationship between observed abusive supervision and prosocial behavior. The foundations of Hypothesis 1 state that observers of abusive supervision experience moral outrage because their moral mandates have been violated. People strive to alleviate this outrage and perceived incongruence between one's values and observed actions by engaging in prosocial behavior to benefit the target of abuse. This process may be strengthened when the victim of abuse has close personal ties with the observer. When the observer and coworker (as the target of abuse) are friends, they share a personal attachment, identity, and greater concern for each other. Based on the close personal tie, moral outrage about the abusive supervisor may be intensified leading to a stronger need to alleviate this feeling, resulting in stronger prosocial reactions of the witness.

Moreover, observers of abusive supervision may experience increased feelings of guilt because they have been accidently advantaged over the abused coworker, who is a close friend. Research found support for this assertion. Some of the strongest survivor guilt reactions were 
found in WWII prison camp survivors, who lost loved ones or close comrades (Neiderland, 1981).

In sum, friendship ties create a greater attachment and identity between the employees which may prompt individuals to have a stronger motivation to come to the aid of their coworker after those have experienced abuse in the workplace. Hence, the following hypothesis is proposed.

Hypothesis 3: Friendship ties moderate the relationship between observed abusive supervision and prosocial reactions such that the relationship is stronger when the observer and victim of abuse share stronger friendship ties.

\section{Organizational Characteristics}

Finally, in addition to characteristics of the individual observer and the relationship between the observer and the victim of abuse, my model proposes that the way the observer views characteristics in the workplace itself would moderate the relationship between observed abusive supervision and prosocial behavior. In particular, I propose that a climate for justice strengthens the relationship.

\section{Justice Climate}

Researchers have expressed great interest in investigating organizational justice at the climate level (e.g., Liao \& Rupp, 2005; Lin, Tang, Li, Wu, \& Lin, 2007; Spell \& Arnold, 2007). Justice climate emerges from individuals’ social environments. Employees form fairness perceptions of the organization through social interaction and information sharing (Mossholder, Bennett, \& Martin, 1998). For example, Roberson (2006) argued that perceptions of justice 
among work group members stimulate sense-making activities within the group, which results in group discussions about the events. These social interactions lead to more consistent fairness perceptions among members, which reflect the justice climate of the work unit.

The importance of justice climate perceptions has been underscored by showing that justice climate represents a significant predictor of employee behavior and attitudes, above and beyond individual-level perceptions of justice (e.g., Liao \& Rupp, 2005). Justice climate in the form of specific facets of justice (e.g., distributive, procedural, informational, and interpersonal) has been linked to a variety of positive outcomes. For instance, Naumann and Bennett (2000) found that procedural justice climate was associated with helping behavior within a work team. Liao and Rupp (2005) showed that procedural, informational, and interpersonal justice climates were predictive of a variety of outcomes such as performance and organizational citizenship behavior. Similarly, Simons and Roberson (2003) showed that both procedural and interpersonal justice climate were related to employee intent to stay at the organization and customer satisfaction.

\section{Organizational vs. Psychological Climate}

Researchers within the climate literature distinguish between organizational climate and psychological climate. An organizational climate refers to workers' collective perceptions of the work environment. In turn, a psychological climate exists at the individual level as the employee generates meaning from the environmental stimuli around them (see James, Choi, Ko, McNeil, Minton, Wright, \& Kim, 2008, for a review). Specifically, employees create meaning and significance of the environment by going through the process of valuation, in which the external 
attributes are perceived and interpreted in light of what the individual values and cherishes. This cognitive process of valuation and interpretation is crucial as the attained values determine an individual's welfare in the organization and the member's organizational well-being (Brown \& Leigh, 1996; James et al., 2008). Overall, a psychological climate assesses environmental aspects that are meaningful to the individual and his/her well-being. It thus reflects an individual attribute as opposed to a collective feature.

Psychological climates represent the meaning people draw from every aspect of their work environment, including job characteristics, supervision and management, coworkers, pay, performance, and equity (James \& Jones, 1974; Parker, Baltes, Young, Huff, Altmann, Lacost, \& Roberts, 2003). Kuenzi and Schminke (2009) stated that climates focused on ethics and justice have been studied as psychological climates.

\section{Overall Justice}

Recently, scholars have suggested justice judgments should be considered at a more general or global level, in the form of overall justice (Colquitt \& Shaw, 2005; Rupp \& Paddock, 2010). Lind (2001) argued that people make holistic judgments about fairness, and that these general experiences of justice drive individuals' behaviors in organizations. Recent empirical research provided support for an overall justice construct (Ambrose \& Schminke, 2009; Holtz \& Harold, 2009; Jones \& Martens, 2009). For example, Ambrose and Schminke found that specific facets of justice influence the formation of overall justice perceptions, which in turn predicted employee attitudes and behaviors. 
Even though scholars have embraced the overall justice construct and have shown that it has important implications (Rupp \& Paddock, 2010), no research has been published yet about the effects of overall justice climate, at either the organizational or psychological level. Thus, I am able to contribute to this line of research by showing that overall justice climate may moderate the relationship between observed abusive supervision and prosocial outcomes. The way the observer views overall justice in the workplace may strengthen the relationship between observed abusive supervision and prosocial behavior toward the victim of abuse. Specifically, the organizational context shapes the salience and meaning of organizational events (Kuenzi \& Schminke, 2009). Hence, overall justice climate may influence (1) how strongly individuals perceive a violation of moral mandates and (2) how strongly they experience survivor guilt after observing abusive supervision toward their coworker. Specifically, in an overall fair work environment, in which employees are treated fairly on a daily basis, individuals may be more strongly morally outraged about abuse, because not only have their moral mandates been violated, but also the values of the organization. Furthermore, individuals' moral mandates, such as treating others with dignity and respect, may also be more salient and instilled in a person who works in an overall fair climate. The perceived violation of moral mandates and perceived incongruence between personal fairness values and abuse in the workplace are softened by engaging in prosocial behavior to aid the victim of abuse.

The observer of abuse may also experience stronger feelings of guilt. In an overall fair work place, witnesses of abuse may be more likely to perceive an accidental advantage over their coworker. The fact that in a fair work environment, the coworker was chosen as a target of abuse while one was not, may elicit stronger feelings of survivor guilt which will be alleviated by 
engaging in prosocial behavior toward the coworker. Overall, stronger moral outrage and violations of moral mandates as well as increased guilt may prompt stronger prosocial reactions toward the victim of abuse. Thus, I propose:

Hypothesis 4: Overall justice climate moderates the relationship between observed abusive supervision and prosocial reactions such that the relationship is stronger under conditions of a high justice climate. 


\section{METHOD}

\section{$\underline{\text { Study } 1}$}

Because my dissertation attempts to cover new grounds in established literatures, I conducted a laboratory experiment with the aim of exploring some of the hypothesized relationships. Thus, the goal of the experiment was to examine the relationship between observed abusive supervision and prosocial reactions of the observer toward the victim of supervisor abuse. I further examined whether interaction effects between observed abusive supervision and friendship ties and observed abusive supervision and moral courage predict variance above and beyond the proposed main effect.

\section{Sample and Procedure}

One hundred and twenty-three undergraduate students were invited to participate in the study. Participation in this study was voluntary and extra credit for their class was provided. All participants were assured confidentiality. One hundred and three students participated in the data collection resulting in a response rate of $83 \%$. The average age of the participants was 24.4 years. Sixty-one percent of the participants were male.

The study used a 2 (high observed abusive supervision vs. low observed abusive supervision) X 2 (strong friendship ties vs. weak friendship ties) between subjects design. Participants were randomly assigned to each condition. Moreover, the moderating variable of moral courage was assessed as an individual difference prior to reading scenarios describing abuse and friendship ties in the workplace. In particular, participants were instructed to read a 
scenario in which they had to imagine they were the employee (observer) depicted in the scenario. The scenarios included descriptions of the employee's immediate supervisor and his abuse toward a coworker.

The description of the supervisor as a highly abusive supervisor was:

"Imagine you have graduated and are a full-time employee at an organization in town. One day at work, you witness your supervisor verbally attack one of your coworkers, who is a very close friend of yours. More specifically, you have to witness that your supervisor puts your good friend down in front of others and tells him/her that he/she is incompetent. Moreover, he is also rude and ridicules the employee.”

In contrast, the description of the leader as a low abusive person was:

"Imagine you have graduated and are a full-time employee at an organization in town. One day at work, you witness your supervisor engage in the following behavior toward your coworker, who is a very close friend of yours. You witness how your supervisor lies to your friend and additionally does not give him/her credit for much of the work he/she has done even though your friend has put a lot of effort into the job.”

I created the high and low observed abusive supervision conditions based on Mitchell and Ambrose’s (2007) distinction between passive-aggressive and active-aggressive abusive behavior. The low observed abuse condition reflected passive behavior whereas the high observed abuse condition reflected active abusive behavior. All abusive behaviors depicted in the scenario stem from Tepper’s (2000) abusive supervision scale.

As already revealed in the scenarios, the description of the friendship ties created a reference to the coworker who was receiving abusive treatment. Either, the participants read about observing mistreatment toward a close friend or simply another coworker. The friendship tie manipulation read as follows in the strong tie condition:

"One day at work, you witness your supervisor verbally attack one of your coworkers, who is a very close friend of yours." 
Finally, the weak friendship tie condition read as follows:

"One day at work, you witness your supervisor engage in the following behavior toward another employee."

Because moral courage is only evidenced by the existence of a threat or risk to the actor, I

included the following description:

"The supervisor is in a high power position since he has input in who gets promoted or even fired. Thus, risks are involved if you tried to stand up for your friend or if you tried to help him/her out. The supervisor may remember your actions and it may have negative consequences for you and your professional life”.

The scenario was followed by a manipulation check for the observed abuse and

friendship tie manipulations, which then were followed by ratings of the prosocial outcome variables including voice behavior and standing up behavior (see Niesta Kayser, Greitemeyer, Fischer, \& Frey, 2010).

\section{Measures}

Responses for all items were made on a five-point response scale where 1 = "strongly disagree” to 5 = “strongly agree,” unless otherwise noted.

Manipulation Check Items. For the manipulation check, I developed two items for observed abusive supervision and two items to assess friendship ties. The abuse items include “The supervisor is abusive toward this employee,” and "The supervisor is rude and unprofessional.” The friendship items for the manipulation check were “The employee, who is treated unfairly, is a good friend of yours," and "You have a close relationship with the unfairly treated employee.” The reliabilities for the scales were $\alpha=.83$ and $\alpha=.97$, respectively. 
Moral Courage. Moral courage was assessed with Sekerka et al.’s (2009) six-item measure of endurance of threat which was taken from the multidimensional scale of professional moral courage. The endurance of threat dimension most closely aligns with my construct definition of moral courage which I defined as the ability to use ethical principles to do what is good, regardless of a threat to self. Employees indicated the extent to which they agreed with statements such as "When I encounter an ethical challenge, I take it on with moral action, regardless of how it may pose a negative impact on how others see me," and "I act morally even if it puts me in an uncomfortable position with my superiors." $(\alpha=.73)$.

Prosocial Behavior. In this study, I examine two types of prosocial behaviors an observer of abusive supervision could engage in. One refers to speaking up or voice behavior and the other refers to standing up behavior. Voice was measured with six items from van Dyne and LePine’s (1998) scale. The voice items were adapted to reflect the participants' voice behavior regarding unethical behaviors of the superior and issues affecting the coworker. Sample items include: "I communicate my opinions about unethical situations to others in the work group even if his/her opinion is different and others in the group disagree with me," and "I speak up in this department about unethical issues such as abuse of employees." $(\alpha=.71)$.

I developed six items to reflect standing up behavior. The items are conceptually closely related to those of moral courage. Specifically, these items reflect the willingness of an observer to engage in "moral courage behavior” as noted by Niesta Kayser et al. (2010). Niesta Kayser and colleagues describe moral courage behavior as a type of prosocial behavior that occurs when the individual is facing a risk or high costs and consequences when performing prosocial behavior. Some sample items include: "I am willing to stand up for the unfairly treated 
employee," and "I am willing to face this ethical dilemma and help out even though I may be at risk," "I am willing to stand up for the employee even though it may put me in an uncomfortable situation with my superiors," "I am going to act on my moral principles and stand up for the unfairly treated employee," "I am willing to stand up for the employee even if I encounter negative consequences," and "Regardless of the risk, I will help and support the employee." $(\alpha=.94)$.

Results

The means, standard deviations, reliabilities, and intercorrelations among the variables are presented in Table 1.

Insert Table 1 about here

\section{Manipulation Check Results}

Before testing the hypotheses, I examined whether the manipulations were successful by conducting one-way ANOVAs. Results indicated that participants in the high observed abusive supervision condition did not report higher observed abuse $(M=4.41, S D=.90)$ than participants in the low observed abusive supervision condition $(M=4.13, S D=.76)$. In turn, results of a one-way ANOVA showed that individuals in the high friendship condition ( $M=$ 4.15, $S D=.98$ ) reported a stronger relationship with the abused coworker than participants in the low friendship condition $(M=2.85, S D=.73)$.

The non-significant manipulation check for observed abusive supervision represents an obstacle for any hypothesis testing. A non-significant difference between the conditions indicates that individuals who were exposed to either low or high observed abuse responded similarly to 
the manipulation check items. This in turn means that the manipulations did not create enough variance between the conditions which is needed to detect any effects in the dependent variable.

This lack of difference between the two conditions may come from two sources. (1) The low abuse condition may have reflected supervisor behaviors that can be perceived as quite abusive by participants, resulting in no significant difference between the low and high abuse condition. (2) The problem may have been rooted in the phrasing of the manipulation check items. As noted above, the low observed abusive supervision and high observed abusive supervision conditions were created based on the passive vs. active aggressive abuse behavior (Mitchell \& Ambrose, 2007). The manipulation check items referred to: “The supervisor is rude and unprofessional” and "The supervisor in this scenario is abusive toward this employee." These items seem too ambiguous and not distinct enough to capture a difference between a low and high abuse condition. Specifically, in both scenarios the supervisor treated another employee in an unfair and abusive manner such that participants tended to respond to the manipulation check items in a similar way. For example, even a supervisor who does not give an employee credit for a certain job (low abuse condition) could be seen as rude and unprofessional.

However, in order to still proceed with some exploratory analyses to examine whether this research is worth exploring, I decided to use the manipulation check items as indicators of the observed abusive supervision and friendship tie construct.

\section{$\underline{\text { Exploratory analyses }}$}

Before conducting the analyses, I assessed a measurement model with confirmatory factor analysis (CFA), using LISREL (8.8) (Jöreskog \& Sörbom, 2006) with maximum 
likelihood estimation. Confirmatory factor analyses (CFA) indicated that the five-factor model with observed abusive supervision, moral courage, friendship ties, voice, and standing up behavior as distinct constructs fit the data well $\left(\chi^{2}=306.09 d f=199, p \leq .001\right.$; SRMR $=.09$, RMSEA = .07 CFI = .93). RMSEA scores equal or below .08 (Hoyle \& Panter, 1995) indicate that the model has a good fit.

All regression results are shown in Table 2. Hypothesis 1 states that observed abusive supervision is positively related to prosocial reactions of the witness of abuse. Regression analyses revealed that observed abusive supervision had a direct and positive influence on standing up behavior $(\beta=.21, p<.05)$, but not on voice behavior. Thus, Hypothesis 1 is partially supported.

Hypothesis 2 suggested that moral courage will moderate the relationship between observed abusive supervision and prosocial reactions of the observer. Regression results revealed no significant interaction effect indicating Hypothesis 2 is not supported.

Hypothesis 3 states that friendship ties moderate the proposed main effect relationship between observed abuse and prosocial reactions. I was able to find partial support for this relationship such that the interaction between observed abuse and friendship ties is significant for standing up behavior $(\beta=.20, p<.01)$, but not for voice. Plotting the interaction graph, using values one standard deviation above and below the mean for each condition (Aiken \& West, 1990) shows that, as predicted, under conditions of strong friendship ties, the relationship between observed abusive supervision and standing up behavior is strengthened (Figure 2). 


\section{Discussion}

First and foremost, the purpose of this study was to explore some of the hypothesized relationships in my dissertation to determine whether this research question was worth pursuing. The experimental study examined the impact of observed abusive supervision on prosocial behavior aimed at benefitting the victim of abuse. Furthermore, I was interested in assessing whether moral courage and friendship ties moderate this relationship. Results reveal some interesting and promising findings indicating some support for my predictions. For example, analyses showed a positive relationship between observed abusive supervision and standing up behavior. In addition, the interaction effect between observed abusive supervision and friendship ties is significant and consistent with my hypothesis. Figure 2 reveals that when strong friendship ties exist between the observer and the victim of abuse, the relationship between observed abusive supervision and standing up behavior is strengthened.

\section{Theoretical contribution}

The finding that individuals are prone to exhibit some type of prosocial behavior to benefit the target of abuse is very interesting and novel within the abusive supervision and third party injustice literature. First and foremost, this contributes to the abusive supervision literature by showing that observing this type of supervisor behavior triggers prosocial reactions in employees, which is contrary to most abusive supervision research. Second, to date, abusive supervision research has primarily focused on employee reactions to their own abuse (Tepper, 2007), with little consideration given to how employees respond when their supervisors mistreat others and they observe this behavior. Greenbaum et al. (2009) were the first to consider the notion of abusive supervision in third party research; however this study has not taken into 
account abuse directed towards the coworker. Instead, the authors focused on customers which are external to the organization.

In terms of third party injustice research, a number of experimental studies have demonstrated that people generally respond to observed injustices by engaging in retributive behavior that serves to punish the wrongdoer (e.g., Turillo et al., 2002). Yet, my findings suggest that some people may also engage in more prosocial forms of restorative justice behavior. This finding further extends similar results that have been presented in recent work by Rupp and Bell (2010) and Greenbaum et al. (2009, 2011). Rupp and Bell found that people who are able to selfregulate their moral behavior are less likely to respond to third-party injustices by punishing the violator with the same behaviors they find offensive. Instead, their findings suggest that these people respond by doing nothing at all (e.g., by not punishing the perpetrator). Extending Rupp and Bell’s findings, Greenbaum et al. demonstrate that some employees are more prone to engage in withdrawal behavior (e.g., turnover) and constructive resistance. The authors argue that individuals high in moral identity are less inclined to show retributive behavior because they feel that causing harm in general is as unacceptable and appalling as the offending behavior of the abusive supervisor.

\section{Limitations}

In spite of some interesting findings, this study has some limitations. In general, laboratory experiments possess certain drawbacks (Shadish, Cook \& Campbell, 2002). For example, undergraduate students served as participants in this experiment. Therefore, this study may lack external validity as undergraduate students are not representative of full time employees in organizations across the nation. Furthermore, I used a very specific hypothetical 
scenario in which the participant had to imagine witnessing abuse done from the supervisor toward another employee. Even though the scenarios appear plausible, other studies should employ different abuse scenarios to see whether abusive supervision can be manipulated and the results from this dissertation can be replicated.

Moreover, I have already noted the drawback of the manipulations describing observed abusive supervision. In addition to the design issues regarding the manipulations and manipulation check items, other concerns include measurement and validity issues of the outcome variables. First of all, the measure of standing up behavior was designed after the German notion of civil or moral courage, which is defined as a prosocial behavior people demonstrate when a threat is present in the environment, and great costs are associated with engaging in helping behavior toward the victim (Niesta Kayser et al., 2010). In order to assess this behavior, I adapted items from the moral courage scale (Sekerka et al., 2009). This in turn can be problematic because the items seem conceptually too closely related to the notion of moral courage as defined by Sekerka and Bagozzi (2007). Therefore, one could argue that this measurement does not truly capture the notion of standing up behavior. A similar issue might exist with the assessment of voice behavior such that the items may not adequately measure the speaking up of an observer to benefit the victim of abuse.

However, the results of the experiment seem promising such that prosocial behavior may occur after witnessing abuse. Tedeschi and Quigley (1996) emphasized the usefulness of employing a multi-method approach when examining organizational phenomena such as aggression. Therefore, I conducted a field study to examine whether the hypothesized relationships in this study hold in an organizational setting. I will examine whether observed 
abusive supervision exerts a positive main effect on prosocial reactions and whether moral courage and friendship ties moderate this relationship. Further, the prosocial reactions are assessed by a newly developed measure of standing up behavior and improved voice items.

\section{$\underline{\text { Study } 2}$}

Sample and Procedure

I collected data from focal respondents and their immediate supervisors from a variety of organizations in the Southeastern United States. University students from predominantly MBA classes and one undergraduate class served as organizational contacts in exchange for extra course credit. The students were instructed by the researcher to recruit a working adult who works at least 20 hours or more per week in an organization, and who was willing to serve as a focal employee. The recruited focal employee was told that the study assesses working relationships between employees and their supervisor. Thus, the focal employee was instructed to identify a specific coworker and their common immediate supervisor. All three participants, focal employee, coworker, and supervisor each filled out separate surveys assessing their own behavior and that of the other two participants. For example, the focal employee answered survey questions about him/herself, the coworker, and supervisor. In turn, the supervisor responded to items regarding the focal employee's behavior toward the identified coworker.

The surveys were administered through secure online websites. Participation was voluntary and participants were insured confidentiality of their responses. A number of researchers have used similar approaches when collecting data (Grant \& Mayer, 2009; Mayer, 
Kuenzi, Greenbaum, Bardes, \& Salvador, 2009; Piccolo, Greenbaum, Den Hartog, \& Folger, 2010).

Similar to Judge et al. (2006), I took a number of steps to ensure that the surveys were completed by the correct individuals. First, when introducing the study, I emphasized the integrity in the scientific process depended on appropriate individuals completing the surveys. Second, when participants submitted their on-line surveys, time stamps and IP addresses were recorded to ensure that the surveys were submitted at different times and from different IP addresses.

I invited approximately 400 students to serve as organizational contacts and these contacts generated responses from 122 participants for a response rate of 30.5\%. The employees were $45.9 \%$ male. $16.8 \%$ identified themselves as having Hispanic heritage. Further, focal employees and coworkers were 68.6\% Caucasian, 6.9\% Asian American or Pacific Islander, 5.8\% African American, 6.7 \% biracial, and 12.6\% marked “other.” The employees had an average age of 30.7 years and an average of 5.9 years of experience with their organization. The supervisors were $66.4 \%$ male. $10.7 \%$ identified themselves as having a Hispanic background. When asking about their racial identity, supervisors indicated that they were $79.5 \%$ Caucasian, 9.0\% African American, 4.1\% Asian American or Pacific Islander, 2.5\% biracial, and 4.1 \% marked other. The supervisors had an average age of 42.6 and shared an average of 10.9 years as work experience.

The focal employee survey contained measures of supervisor abuse of coworkers, moral courage of the focal employee, friendship ties between the focal employee and the coworker, and 
demographic questions. The supervisor survey contained measures of the prosocial outcomes standing up behavior and voice.

\section{Measures}

Responses for all items were made on a seven-point response scale where 1 = "strongly disagree” to 7 = “strongly agree,” unless otherwise noted.

Observed Abusive Supervision. To assess observed abusive supervision, I employed Mitchell and Ambrose's (2007) 5-item version of Tepper's (2000) 15-item abusive supervision scale. Because my interest lies in assessing third party reaction to abusive supervision, items were modified to reflect employee perceptions of abuse targeted toward the coworker, rather than toward the self. Employees were asked to rate the extent to which they agreed with statements such as "My supervisor ridicules my coworker," and "My supervisor makes fun of my coworker.” $(\alpha=.96)$.

Moral Courage. Moral courage was assessed with Sekerka et al.’s (2009) six-item measure of endurance of threat taken from the multidimensional scale of professional moral courage. Employees indicated the extent to which they agreed with statements such as "When I encounter an ethical challenge, I am the kind of person who takes it on with moral action, regardless of how it may pose a negative impact on how others see me.” $(\alpha=.70)$.

Friendship Ties. I assessed the presence of friendship ties using 9-items from a 12-item friendship tie strength scale developed by Petróczi, Nepusz, and Bazsó (2007). These nine items measured trust, relationship, companionship, closeness, and intimacy between the focal employee and the specific coworker. The three items that were not included assess the social 
network notion of multiplexity which was not part of my specific interest when measuring the relationship between the observer and the victim. Finally, I adapted the items to reflect the relationship between the focal employee and the abused coworker. Some sample items include: “I trust my coworker (for example they know your name, email address, password to your computer or email or phone)," “I have private correspondence with my coworker”, and “I consider my coworker a friend.” $(\alpha=.89)$.

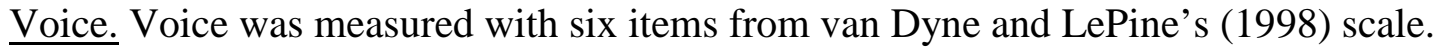
The voice items were adapted to reflect voice behavior of the focal employee to improve the situation of the coworker. The supervisor, who was informed by the observer (focal employee) who the corresponding coworker was in the scenario, rated items such as "My subordinate develops and makes recommendations concerning issues that affect his/her coworker" and "My subordinate gets involved in issues that might affect the quality of his/her coworker's work life.” $(\alpha=.90)$.

Standing up Behavior. I developed nine items in order to assess this construct. Supervisors rated the extent to which the focal employee would stand up for the victim and the extent to which the focal employee would side with and support the target of abuse. Again, the supervisor knew which subordinates the items were referring to. All nine items are listed in the appendix. $(\alpha=.88)$.

Control Variables. In testing the hypotheses, I controlled for demographic variables (age and gender) (Becker, 2005). 
Results

The means, standard deviations, and intercorrelations among the variables are presented in Table 3.

\section{Insert Table 3 about here}

The measurement model was assessed with confirmatory factor analysis (CFA), using LISREL (8.8) (Jöreskog \& Sörbom, 2006). Given the large number of items to consider compared to my sample size, I used a parceling approach with manifest indicators of latent variables for the friendship and standing up behavior measures (e.g., Bagozzi \& Edwards, 1998; Landis, Beal, \& Tesluk, 2000). The analyses indicated that the five-factor model with observed abusive supervision, moral courage, friendship ties, voice, and standing up behavior as distinct constructs fit the data well $\left(\chi^{2}=369.11, d f=220, p \leq .001 ;\right.$ SRMR $=.07$, RMSEA $=.075$ CFI $=$ .92). RMSEA scores equal or below .08 (Hoyle \& Panter, 1995) indicate that the model has an acceptable fit. I compared the five-factor to a three-factor and to a one-factor model. The threefactor model, which was set to load the outcome variables and moderating variables as single factors, had a poor fit $\left(\chi^{2}=663.42, d f=227, p \leq .001\right.$; $\left.\mathrm{SRMR}=.12, \mathrm{RMSEA}=.13, \mathrm{CFI}=.79\right)$. A chi-square difference test showed that the five-factor model had a significantly better fit than the three-factor model $\left(\chi^{2}\right.$ difference $\left.=294.31, d f=7, p \leq .001\right)$. Similarly, the one-factor model had a poor fit $\left(\chi^{2}=1453.73, d f=230, p \leq .001 ; \operatorname{SRMR}=.20, \operatorname{RMSEA}=.21, \mathrm{CFI}=.55\right)$, and a chisquare difference test showed that the five-factor model had a significantly better fit than the one-factor model $\left(\chi_{\text {difference }}^{2}=1084.62, d f=10, p \leq .001\right)$.

Following Cohen, Cohen, West, and Aiken, (2003), I mean-centered all predictor variables prior to testing my hypotheses. Furthermore, all regression results are shown in Table 
4. Hypothesis 1 states that observed abusive supervision elicits positive reactions in the witness of abuse. Contrary to my predications, hierarchical regression analyses revealed a significant yet negative main effect between observed abusive supervision and voice $(\beta=-.17, p<.10)$, and a negative relationship between observed abusive supervision and standing up behavior $(\beta=-.24$, $p<.01)$. Thus, Hypothesis 1 was not supported.

Hypothesis 2 suggested that moral courage moderates the relationship between observed abusive supervision and prosocial behaviors of the observer to benefit the victim of abuse. Results show no significant interaction effect between observed abusive supervision and moral courage on prosocial reactions. Hence, Hypothesis 2 is not supported.

Hypothesis 3 predicted that friendship ties would moderate the relationship between observed abuse and prosocial behavior. Regression results revealed a significant interaction effect between friendship ties and observed abusive supervision on standing up behavior $(\beta=0.29, p<.01)$. Figure 3 illustrates the resulting interaction effect. Contrary to my predictions, the pattern of the interaction shows that when the observer and the target of abuse share strong friendship ties, the negative relationship between abuse and standing up behavior is mitigated.

\section{Discussion}

The goal of this study was to provide a field test of part of my theorized model. Analyses revealed a negative relationship between observed abusive supervision and prosocial reactions of the witness of abuse. Furthermore, moral courage did not moderate the proposed relationship. In turn, results demonstrated that friendship ties influenced the relationship between observed abusive supervision and standing up behavior. Results show that when the observer and the 
target of abuse share friendship ties, the negative relationship between observed abusive supervision and prosocial reactions is weakened.

\section{Theoretical Implications}

Overall, my results are inconsistent with my predictions and the exploratory results from Study 1 . This shows that differences occurred between a lab and field setting suggesting that prosocial behavior after witnessing abuse in an organization may be context specific. That is, there may be conditions or circumstances in the field that prompt the observer to react differently. One explanation may be the continuous relationship the observer has with the supervisor. As noted previously, supervisors represent a higher power in the organization and control employees’ resources such as pay or promotion. Research has shown that subordinates in organizations are hesitant to engage in behavior that goes against the supervisor. In particular, research within the abuse literature has found that people generally tend to redirect their anger and frustration toward a less powerful target (e.g., Hoobler \& Brass, 2006; Restubog et al., 2011).

Another explanation why an observer is unlikely to exhibit prosocial behavior after witnessing abuse could be the perceived relationship and interactions between the supervisor and target of abuse. Bowes-Sperry and O’Leary-Kelly (2005) argue the relationship between the perpetrator and target is of great importance when an observer is contemplating to engage in any kind of action to benefit the victim. For example, the observer may think that the coworker deserves the abuse somehow based on his or her actions or prior interactions with the supervisor. Research shows support for this assumption such that when the third party observer perceives the target of abuse deserves this treatment, helping behavior is inhibited (Niehoff et al., 1998). 
Finally, this finding of a negative relationship between observed abusive supervision and negative reactions of the observer is consistent with research from the bullying (e.g., Parzefall \& Salin, 2010) and incivility literature (e.g., Porath \& Erez, 2007). This research suggests that observers of unfairness experience the same feelings of injustice and psychological contract breach as the victim, which leads the person to develop the same negative attitudes and reactions. Porath and Erez (2007) in turn argued that observers of incivility display lower levels of citizenship behavior as a result of displaced aggression. Specifically, the witness of incivility develops feelings of anger and aggression and exhibits those by withholding citizenship behavior towards others, even though the person requesting help was not responsible for the wrongdoing.

My results further show that this negative relationship between observing abuse and prosocial reactions is weakened when the observer and victim possess close friendship ties with one another. Research on the notion of oneness and social identity theory (Tajfel \& Turner, 1986) provide rationale for this interaction effect. When people experience a sense of oneness, they see more of themselves in the other person, share a common identity, and feel closely related to this individual. Feelings of oneness translate into greater empathy which means that one individual experiences some of the same feelings as the other person, and shows greater concern for the other party (Cialdini et al., 1997). Similar to oneness, when people are friends they also view themselves as part of the same social ingroup. Being part of an ingroup strengthens the "we” feeling of members and fosters solidarity (Hogg \& Hains, 1998). Overall, when the victim of abuse shares close friendship ties with the observer, feelings of oneness, closeness, and greater identity serves as a buffer to the negative effect of abuse in the workplace, 
such that employees still show greater support for one another compared to when the coworkers do not share close personal ties.

Even though contradictory to my predictions, these findings still provide new insights to the literature on abusive supervision. Specifically, I examine the notion of third party abusive supervision toward coworkers in a field setting. Recent empirical research explores abusive supervision toward customers, however, has neglected a focus on how observers of abuse may react when the victim of abuse is an immediate coworker. Further, research on oneness and social identity can inform the abusive supervision literature by showing that negative reactions of abuse in the workplace can be mitigated when employees share a stronger common identity and a greater feeling of oneness. Thus far, only a limited number of studies explored conditions that show neutralizing effects on abusive behavior in the workplace (e.g., Harvey et al., 2007).

Overall, Study 2 contributes to the abusive supervision and third party injustice literature by showing that close personal ties buffer the negative effects of abusive supervision in the workplace. To test my full theoretical model, I conducted a third study. Accordingly, the goal of Study 3 is to not only investigate the impact of individual and relational characteristics on the relationship between observed abuse and prosocial behavior, but also organizational characteristics in the form of overall justice climate. Further, I will extend previous findings by including helping behavior as another outcome variable that captures prosocial reactions toward the victim of abuse. 


\section{Study 3}

Sample and Procedure

The method of recruiting participants and collecting data was the same process as in Study 2. I was able to collect data from focal respondents and the immediate supervisors from a variety of organizations. Both participants answered questions about themselves and other identified people in the triad relationship between the focal employee, the coworker, and supervisor. The surveys were administered through secure online websites and I assured that the scientific process was not compromised by, among other things, recording IP addresses.

I invited approximately 400 students to serve as organizational contacts. These responses created usable dyads from 157 participants for a response rate of 39.3\%. Just over half of the employees (54.7\%) were male, and 16.4\% identified themselves as having Hispanic heritage. Overall, 64.8\% of employees were Caucasian, 5.8\% Asian American or Pacific Islander, 11.9\% African American, 5.7\% biracial, and 10.7\% marked “other.” The employees had an average age of 25.5 years and an average of 3.7 years of experience with their organization. The supervisors were $60.2 \%$ male and $10.8 \%$ identified themselves as having a Hispanic background. When asking about their racial identity, supervisors indicated that they were $74.1 \%$ Caucasian, 8.0\% African American, 5.9\% Asian American or Pacific Islander, 1.5\% biracial, and 9\% marked other. The supervisors had an average age of 38.1 and shared an average of 8.9 years as work experience.

The focal employee survey contained measures of supervisor abuse of coworkers, moral courage of the focal employee, friendship ties between the focal employee and the coworker, overall justice climate, the focal employee's own abuse from the supervisor (as a control), and 
demographic questions. The supervisor survey contained measures of the prosocial outcomes standing up behavior, voice, and helping behavior.

\section{Measures}

Some of the same measures were utilized as in Study 2. Responses for all items were made on a seven-point response scale where 1 = "strongly disagree” to 7 = "strongly agree," unless otherwise noted.

Observed Abusive Supervision. To assess observed abusive supervision, I employed Mitchell and Ambrose’s (2007) 5-item version of Tepper’s (2000) abusive supervision scale. $(\alpha=.91)$.

Moral Courage. Moral courage was assessed with Sekerka et al.’s (2009) six-item measure of endurance of threat which came from the multidimensional scale of professional moral courage. $(\alpha=.69)$.

Friendship Ties. Friendship ties were assessed using 9-items from a 12-item scale developed by Petroczi et al. (2007). These nine items measured the trust, relationship, companionship, closeness, and intimacy between the employees. $(\alpha=.91)$.

Overall Justice Climate. Justice climate was measured using Ambrose and Schminke’s (2009) six-item scale which assesses employees’ perceptions of overall justice in their organization. I modified the items to reflect the department and organization as the referent indicating individuals’ perceptions of the overall fairness in their work environment as opposed to how fairly an individual is treated. For example, employees rated items such as "Overall, 
people in my department are treated fairly by my organization," and "Usually, the way things work around here is fair.” $(\alpha=.96)$.

Helping Behavior. I measured helping behavior using five items from the organizational citizenship behavior scale developed by Podsakoff, MacKenzie, Moorman, and Fetter (1990). The scale was adjusted to reflect helping behavior from the focal employee, who served as the observer, toward the coworker who presented the target of abuse. For assessing helping behavior and all other prosocial outcomes, the supervisor was informed by the focal respondent who the corresponding coworker was the questions referred to. The supervisor rated the extent to which the observer engaged in helping behavior toward the victim. For example "My subordinate, who asked me to fill out this survey, helps his/her coworker when they have been absent and return to work," and "My subordinate is always ready to lend a helping hand to his/her coworker." $(\alpha=.91)$.

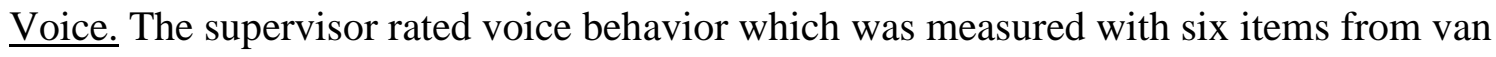
Dyne and LePine’s (1998) scale. $(\alpha=.93)$.

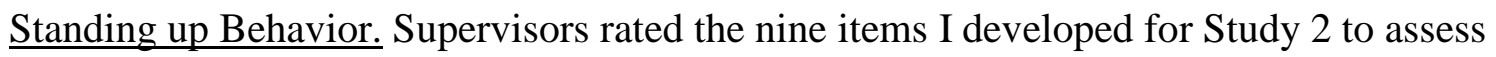
this construct. $(\alpha=.88)$.

Control Variables. In testing the hypotheses, I controlled for demographic variables (age and gender). I further controlled for abuse of the focal employee (Greenbaum et al., 2009), using Mitchell and Ambrose’s 5-item measure of abusive supervision. By controlling for abuse of the focal employee, I can rule out that the observers reactions are due to his/her own abuse. $(\alpha=$ $.86)$. 
Results

The means, standard deviations, and intercorrelations among the variables are presented in Table 5.

\section{Insert Table 5 about here}

I assessed the measurement model using LISREL (8.8) (Jöreskog \& Sörbom, 2006) with maximum likelihood estimation. As in Study 2, a parceling approach using manifest indicators of latent variables was used for the friendship tie and standing up behavior measures (e.g., Bagozzi \& Edwards, 1998; Landis et al., 2000). The CFA showed that the eight-factor model with the focal employee’s ratings of abusive supervision toward him/her, observed abusive supervision, moral courage, friendship ties, overall justice climate, voice, helping, and standing up behavior as distinct constructs fit the data well $\left(\chi^{2}=1141.43, d f=674, p \leq .001\right.$; $\mathrm{SRMR}=.07$, RMSEA $=$ $.066 \mathrm{CFI}=.93)$. I compared the eight-factor to a four-factor and to a one-factor model. The fourfactor model, in which the outcome variables and the moderating variables were set to load onto single factors, had a poor fit $\left(\chi^{2}=2417.61, d f=696, p \leq .001 ; \operatorname{SRMR}=.11\right.$, RMSEA $=.13$, CFI $=.81$ ). A chi-square difference test showed that the eight-factor model had a significantly better fit than the four-factor model $\left(\chi^{2}\right.$ difference $\left.=1276.18, d f=22, p \leq .001\right)$. By the same token, the one-factor model had a poor fit $\left(\chi^{2}=6102.03, d f=702, p \leq .001 ; \operatorname{SRMR}=.21, \mathrm{RMSEA}=.22\right.$, CFI $=.59)$. The chi-square difference test showed that the eight-factor model had a significantly better fit than the one-factor model $\left(\chi_{\text {difference }}^{2}=4960.60, d f=28, p \leq .001\right)$.

Prior to testing my hypotheses I mean-centered all predictor variables (Cohen et al., 2003). In Hypothesis 1, I predicted observed abusive supervision would positively impact prosocial reactions to benefit the target of abuse. Hierarchical regression analyses revealed that 
contrary to my predictions, no significant main effect was found between observed abusive supervision and any of the three prosocial behaviors of the focal employee toward the coworker. Thus, Hypothesis 1 was not supported (see all regression results in Table 6).

Hypothesis 2 suggested that moral courage would moderate the relationship between observed abusive supervision and prosocial behaviors of the observer. Results for this interaction demonstrated no significant effect on any of the three prosocial behaviors directed to aid the coworker. This shows Hypothesis 2 was not supported.

In Hypothesis 3, I stated that friendship ties between the observer and victim moderates the proposed main effect relationship. Regression results did not reveal a significant interaction effect between friendship ties and observed abusive supervision on any of the three outcome variables. Therefore, Hypothesis 3 is also not supported.

Hypothesis 4 suggested that the observer's perceptions about overall justice climate in the workplace would impact the relationship between observed abuse and prosocial behavior. Consistent with my predictions for this hypothesis, results reveal a significant interaction between observed abuse and overall justice climate on standing up behavior $(\beta=0.11, p<.05)$ and voice behavior $(\beta=.14, p<.05)$ of the observer. Thus, Hypothesis 4 is partially supported such that overall justice climate moderated the relationship between observed abusive supervision and two out of the three prosocial outcomes.

Following Aiken and West (1991), I plotted all significant interactions using values one standard deviation above and below the mean for each condition. Figures 4 and 5 illustrate the resulting interaction effects. Consistent with my predictions, the plots reveal that when employees work in an overall fair climate, the relationship between observed abusive supervision 
and standing up behavior and observed abusive supervision and voice, respectively is strengthened.

\section{Discussion}

Overall, the goal of this second field study was to test my full theoretical model. Study 3 shows no significant main effect of observed abuse on prosocial behavior. However, when the observer of abuse perceives the work environment as generally fair, he/she is more inclined to engage in prosocial behavior to benefit the victim of abuse.

\section{Theoretical Implications}

This study shows that under some conditions, observing abusive supervision can elicit prosocial behavior. This field study further extends research on abusive supervision and third party injustice as most studies show that individuals engage in retributive or withdrawal behavior when observing third party injustice. Recent third party observer research states that individuals regulate their emotions and behavior to neglect retributive behavior and in turn do nothing at all (Rupp \& Bell, 2010), withdraw, or engage in constructive resistance (Greenbaum et al., 2011). I am able to extend this line of thinking by showing that observers of abuse are prone to act more prosocially toward the victim when they perceive their work environment to be fair compared to when they work in an unfair work climate.

Fairness in the workplace influences how strongly individuals perceive a violation of moral mandates and how strongly they experience survivor guilt after observing abusive supervision toward their coworker. In a fair work environment, observers may be more strongly outraged about the abuse because fairness is not only part of the self, but also fostered in the 
workplace. Furthermore, individuals' moral mandates, such as treating others with dignity and respect, may also be more salient and instilled in a person who works in an overall fair climate that supports these personal values. The perceived violation of moral mandates and identity incongruence in turn may prompt increased prosocial behavior to benefit the victim of abuse.

Furthermore, the observer of abuse may also experience stronger feelings of guilt. In an overall fair work place, witnesses of abuse may be more likely to perceive an accidental advantage over their coworker. The fact that in a fair work environment the coworker was chosen as a target of abuse while one was not may elicit stronger feelings of survivor guilt which will be alleviated by engaging in prosocial behavior toward the coworker.

Another reason why individuals may be prone to act prosocially in a fair work climate compared to an unfair climate might be that the abusive behavior of a supervisor represents a legitimate reason to exhibit prosocial behavior toward a victim. Research within the team literature shows that team members' backing up behavior is driven by perceptions of legitimacy. That is, helping behavior toward another group member only occurs, when the observers perceive the reason for providing help is appropriate and legit (Porter, Hollenbeck, Ilgen, Ellis, West, \& Moon, 2003). For example, the authors found that if a highly conscientious person with an extreme work overload requests help, other team members perceive this reason as legitimate and engage in backing up behavior. On the contrary, if the observer does not perceive legit reasons to aid another person, helping behavior is withheld. Drawing on research of legitimacy, observing abusive supervision toward a coworker in a fair work environment may represent a legitimate reason for observers to act and show prosocial behavior because individuals are 
generally not treated this way in the organization and this behavior is not compliant with organizational norms.

Overall, this study not only extends research on abusive supervision and third party injustice, but also research on overall justice climate. Specifically, this research shows that overall justice perceptions influence the relationship between observed abusive supervision and observer prosocial reactions above and beyond other moderating variables such as friendship ties and moral courage. This further shows that the notion of overall justice is an important predictor of employee behavior and relationships in organizations. 


\section{GENERAL DISCUSSION}

The goal of this dissertation was to examine potential prosocial reactions to abusive supervision in the workplace. Furthermore, I sought to investigate abusive supervision with a third party lens. Finally, I was interested in extending research on third party injustice by showing that individuals do not always engage in retributive behavior. Instead, under some conditions, people seem inclined to aid the victim of abuse.

Drawing on Skitka’s VPM (2002) and research on guilt, I suggested that observers of abusive supervision exhibit prosocial behavior to benefit the target of abuse. Skikta's VPM states that people possess moral mandates which they hold dear. Once these moral mandates are violated individuals feel morally outraged and perceive incongruence between the environment and their morals, which they like to alleviate by engaging in good behavior toward others, a behavior know as moral cleansing (Zhong \& Liljenquist, 2006). Furthermore, observers of abusive supervision may experience survivor guilt because they find themselves better of as another person in the work group. Survivor guilt has been shown to increase prosocial behavior toward other members (Wayment et al., 1995). Finally, I argued that individual, relational, and organizational characteristics strengthen the relationship between observed abusive supervision and prosocial reactions of the observer.

Results from a laboratory experiment and Study 2 show that friendship ties between the victim of abuse and the observer influence the relationship between observed abusive supervision and prosocial behavior. Further, I found that overall justice climate influences the 
proposed main effect relationship above and beyond any other moderating variables, indicating that prosocial reactions to abusive supervision depend on fairness in the workplace (Study 3).

The findings extend research on abusive supervision and third party injustice in several ways. First and foremost, my findings extend research on abusive supervision by examining observer reactions to abuse instead of focusing on the behaviors the victim of abuse engages in. Thus far, research on abusive supervision has mainly examined how targets of abuse react to mistreatment, neglecting the fact that others observe abusive behavior. Only within recent years, scholars have started to explore third party reactions to observing abuse in the workplace (e.g., Greenbaum et al., 2009, 2011; Mitchell, Vogel, \& Folger, 2012). Hence, this research will nicely contribute to this emerging stream.

At the same time, my dissertation extends research on abuse and third party injustice by showing that individuals do not always engage in retributive (Skarlicki \& Rupp, 2010) or withdrawal behavior (Rupp \& Bell, 2010) when observing third party injustice. Instead, results show that under some conditions employees engage in prosocial behavior after witnessing abusive supervision toward a coworker. This shows that abusive supervision in the workplace can in some circumstances influence positive reactions amongst employees. Studies 1 and 2 show that friendship ties between the observer and target of abuse influence an observer’s display of prosocial behavior. These results are consistent with previous theorizing on third party abuse and findings from the social identity literature. As Mitchell et al. (2012), as well as BowesSperry and O’Leary-Kelly (2005) argue, people similar to us, or those whom we share a common identity with, are more likely to benefit from positive reactions of the observer after being the target of abuse. Further, research found that people who have close ties, or are part of a common 
ingroup, share greater empathetic concerns for one another, which in turn impacts prosocial behavior (e.g., Cialdini et al., 1997).

Interestingly, my findings reveal that when the contextual factor of overall justice climate is present, it predicts the relationship between observing abusive supervision and prosocial reactions of the observer above and beyond moral courage and friendship ties. That is, results show people are more prone to act prosocially to benefit the victim of abuse when they perceive their work environment as fair compared to when they work in an unfair climate. This seems to suggest that individuals experience the strongest moral reactions and violations when working in a fair climate. In particular, when working in an overall fair work environment, individuals may feel a stronger sense of guilt due to the accidental advantage over the coworker. Furthermore, the transgression by the supervisor may not only violate morals of the individual, but also the standards and values of the organization which further outrages the person and drives him/her to act prosocially to benefit the target. Finally, an overall fair work climate may also heighten psychological states that prompt an observer to engage in prosocial behavior after witnessing abuse. For example, being in a fair work environment may create a type of psychological safety necessary for the witness to direct prosocial behavior toward a victim. Research has shown that psychological safety facilitates prosocial actions including voice behavior (e.g., Detert \& Burris, 2007).

In addition to extending research on abusive supervision and third party injustice, these findings also contribute to the emerging literature on overall justice and overall justice climate. Only a limited amount of empirical research examines the moderating influence of overall 
justice. My results demonstrated that overall justice is an important construct that influences employee behavior above and beyond other characteristics.

Finally, this dissertation attempts to shed light on the influence of moral courage on the relationship between observing abuse and benefitting a victim. Moral courage, the ability to use ethical principles and do what is right, regardless of a threat to the self, has received increased attention within the behavioral ethics literature (e.g., Sekerka et al., 2009). However, all three studies did not reveal a significant effect of moral courage on the proposed main effect relationship. Some explanations for this null finding may be the level of moral intensity represented by abusive supervision, or the ambiguity existent in the workplace (Bowes-Sperry \& O’Leary-Kelly, 2005). For example, depending on the workplace, it may be acceptable to yell at subordinates as it could be considered a motivational approach to increase performance. This in turn could reduce the level of moral intensity for the observer. Furthermore, it adds ambiguity to the situation and it may be difficult for the observer to classify the severity of the transgression. Drawing on trait-activation theory (Tett \& Burnett, 2003; Tett \& Guterman, 2000), individuals need to perceive certain cues from the immediate environment to be able to express a trait they possess. Therefore, my findings suggest that observing abuse in the workplace may not provide the relevant cues needed to express the trait of moral courage such that a more severe act of unfairness (e.g., physical violence) is needed to trigger an observer’s moral courage. Research within the bystander literature has found that more severe transgressions with high potential danger increased the likelihood of people to help the victim (Fischer, Greitemeyer, Pollozek, \& Frey, 2006). To further increase our understanding of moral courage in the workplace, I encourage future research to examine its role when witnessing unfair behavior. 
In all, this dissertation contributes to the research on abusive supervision and third-party injustice by showing that under some conditions observing abuse toward a coworker triggers prosocial behavior to benefit the victim of abuse. Furthermore, this research adds to the growing stream of overall justice research by demonstrating and emphasizing the importance of a fair climate in the workplace.

\section{$\underline{\text { Limitations }}$}

All studies have limitations and my dissertation is no exception. Both field studies were collected in a cross-sectional manner which limits my ability to infer causality because all variables were assessed at a single point in time. In order to assess causality between variables and relationships, one necessary condition lies in assessing the predictor variable prior to the dependent variable (Schwab, 1980).

Furthermore, all surveys were administered via online surveys which may imply common method variance (Podsakoff, MacKenzie, Lee, \& Podsakoff, 2003). Even though common method variance might be a concern, I have been able to counter the effects of common method variance by collecting my predictor variables from the focal employee and the outcome variables from the supervisors. Podsakoff et al. state that "the advantage of this procedure is that it makes it impossible for the mindset of the source or rater to bias the observed relationship between the predictor and criterion variable, thus eliminating the effects of consistency motifs, implicit theories, social desirability tendencies, dispositional and transient mood states, and any tendencies on the part of the rater to acquiesce or respond in a lenient manner” (p.887). 
Another limitation in this study is the lack of assessing potential mediating mechanisms. Specifically, I hypothesize about Skitka’s (2002) value protection model, including moral mandates and moral cleansing. Furthermore, I theorize about feelings of guilt the observer experiences. However, I did not assess these mediating mechanisms which limits my ability to truly state that these mechanisms operate between the link of observed abusive supervision and prosocial reactions.

A fourth limitation of this dissertation may be the fact that I describe overall justice climate as an organizational characteristic that influences the relationship between observed abusive supervision and prosocial reactions. In the section on overall justice climate, I debate the differences between an organizational climate and a psychological climate, and clarify that I assess overall justice climate as a type of psychological climate in this dissertation. However, some people may question whether a psychological climate represents an organizational characteristic. Therefore, potential validity issues could arise because organizational characteristics are generally defined as aggregated perceptions of multiple raters of fairness in the workplace compared to only one source of ratings.

Validity concerns may also be raised regarding the friendship tie variable. Even though Petróczi et al.’s (2007) scale assesses the strengths of friendship between members, some of the scale items might not adequately reflect the notion of friendship ties but rather personal relationships instead. For example, one item refers to whether the observer would ask his/her coworker for a favor. This item represents closeness between individuals, however, it may be questioned whether this item indeed reflects ties between friends. 


\section{$\underline{\text { Future Research }}$}

This dissertation examines prosocial reactions to observed abusive supervision and extends the literatures of abusive supervision as well as third party injustice. Because only a limited amount of research has examined positive outcomes of abusive supervision in organizations and third party injustice research, future research is encouraged to paint a fuller picture of the kind of behaviors third party observers of abuse in organizations may display. Past research (Rupp \& Bell, 2010) has noted that not all individuals respond to injustice with the same intention to punish the transgressor. My findings extend this line of thinking by showing that under some conditions, third party observers exhibit increased prosocial behaviors toward another individual. Future research might examine whether positive behaviors can also be directed to the whole work group, the organization, or one's own performance.

Furthermore, it is important to focus on other moderating variables that influence this relationship. For example, my research shows that contextual variables influence how employees may act when observing injustice done to others. Future research could examine other contextual influences that could impact reactions to abuse and prosocial behavior such as an organization's structure. Some research on structure demonstrates that employees perceive different levels of behavioral free space and control which influence peoples' reactions to abuse in the workplace (Mitchell, Priesemuth, Schminke, \& Vogel, 2011).

Future research may also examine potential three way interaction effects. For example, I found that friendship ties and overall justice climate separately influenced the relationship between observed abusive supervision and prosocial reactions. However, it is possible that a three way interaction between abusive supervision, friendship ties, and justice climate exists, 
such that prosocial reactions may be further pronounced when the observer perceives their work environment to be generally fair, and the victim of abuse is a good friend of the witness. Furthermore, as noted above, it may be promising to examine a three way interaction including moral courage and other notions such as moral intensity or overall justice climate. It could be that moral courage only comes to the forefront under certain conditions. For example, drawing on strong and weak situations (Mischel, 1973), working in a fair work environment, in which certain norms of fairness are enforced, may present a strong situation in which the expression of individual differences is inhibited. In turn, a climate that lacks fairness introduces more uncertainty and ambiguity prompting individual differences to surface.

Finally, I encourage future research to explore potential mediating mechanisms of my model. As noted in the limitation section, I hypothesize about moral mandates, identity violations, and guilt reactions to abuse. However, other mechanisms such as pure deontic reactions (Mitchell et al., 2012) may also be at play here. One difference between moral mandates and deontic justice lies in severity of perceived injustice. Compared to research on deonance and third party injustice, individuals hold moral mandates about severe issues such as human rights, freedom, and abortion. It is a violation of these issues that cause a person's threat to the moral self and prosocial reactions. Therefore, it may be important to know whether abusive supervision in the workplace also triggers moral mandate and identity violations, or whether more deontic emotions are activated. Recent research suggests that less severe distributive fairness issues, such as restricting fan behavior at football games, resulted in identity violations of students (Mayer, Greenbaum, Kuenzi, \& Shteynberg, 2009). However, more 
research in this arena is required to explore which type of unfairness prompts the moral self to be violated compared to experiencing solely moral anger and outrage.

\section{$\underline{\text { Practical Implications }}$}

This research emphasized the importance of fairness in the workplace and good relationships between coworkers. It shows that even in times of abuse, positive reactions occur when employees perceive that they work in a fair work environment compared to an unfair workplace. Thus, it is extremely important for management and organizations to foster a fair climate. Fair climates may prompt employees to not tolerate unfair or abusive behavior. It further makes unfair acts more salient in the workplace which may encourage people to act against seen injustice.

Furthermore, this research emphasizes the importance of close ties between employees. When employees share close personal ties with one another, they perceive a stronger common identity which fosters prosocial behavior and solidarity (Tajfel \& Turner, 1986). Organizations could strengthen employee relationships to create a stronger identity and sense of oneness. For example, management could arrange monthly or bi-monthly employee events or team building exercises in which people have the opportunity to get to know each other on a more personal level.

Despite the fact that justice climate and close ties between coworkers dampen the effect of abuse in organizations or even foster prosocial reactions among employees, the findings of dissertation do not encourage abusive behavior in organizations to increase supportive behavior in employees. As noted above, results illustrate a strong negative effect between observed 
abusive supervision and employee behavior. Therefore, I urge organizations and management to reduce abusive behavior in organizations by potentially putting increased sanctions or punishments in place. Research shows that deviant behavior in organizations is softened when sanctions and punishments are present (e.g., Robinson \& O’Leary-Kelly, 1998). Furthermore, organizations could sponsor ethics training for managers and emphasize the importance of treating employees with dignity and respect and focusing on ethical behavior. 


\section{CONCLUSION}

This dissertation examined prosocial reactions to observed abusive supervision and the conditions under which this relationship is strengthened. Research on abusive supervision is extended in two distinct ways by exploring third party reactions to abuse and showing that under some conditions employees engage in increased prosocial behavior after witnessing abusive supervision toward a coworker. These findings also contribute to research on third party injustice which has primarily focused on retributive justice reactions after witnessing unfair experiences. Perceptions of overall justice climate influence the relationship between observed abusive supervision and prosocial reactions above and beyond other factors indicating the importance of justice in the workplace. 
APPENDIX A: TABLES 
Table 1: Descriptive Statistics, Reliabilities, and Correlations of Study 1 Variables

\begin{tabular}{|c|c|c|c|c|c|c|c|}
\hline Variables & $M$ & $S D$ & 1 & 2 & 3 & 4 & 5 \\
\hline 1. Observed Abusive Supervision & 4.29 & .85 & $(.83)$ & & & & \\
\hline 2. Friendship Ties & 3.50 & 1.08 & $.21 *$ & $(.97)$ & & & \\
\hline 3. Moral Courage & 3.63 & 60 & .10 & .00 & $(.73)$ & & \\
\hline 4. Voice & 3.79 & .47 & .12 & .07 & $.26 * *$ & $(.71)$ & \\
\hline 5. Standing up Behavior & 3.72 & .77 & $.19^{\dagger}$ & $.23 *$ & $.45^{* *}$ & $.35 * *$ & $(.94)$ \\
\hline
\end{tabular}


Table 2: Study 1 Results of Regression Analysis

\begin{tabular}{|c|c|c|}
\hline Variables & Voice & $\begin{array}{c}\text { Standing up } \\
\text { Behavior }\end{array}$ \\
\hline
\end{tabular}

\begin{tabular}{|l|l|l|l|l|}
\hline \multicolumn{2}{l}{ Step 1 } & \multicolumn{1}{c}{ Step 2 } & Step 1 & Step 2 \\
\hline Constant & $3.79^{* *}$ & $3.80^{* *}$ & $3.73^{* *}$ & $3.69^{* *}$ \\
\hline $\begin{array}{l}\text { Observed Abusive } \\
\text { Supervision }\end{array}$ & 0.05 & 0.04 & 0.10 & $0.21^{*}$ \\
\hline Friendship Ties & 0.02 & 0.02 & $0.15^{*}$ & 0.09 \\
\hline Moral Courage & $0.20^{* *}$ & $0.20^{*}$ & $0.57^{* *}$ & $0.61^{* *}$ \\
\hline $\begin{array}{l}\text { Observed Abusive } \\
\text { Supervision X Moral } \\
\text { Courage }\end{array}$ & & -0.05 & & -0.08 \\
\hline $\begin{array}{l}\text { Observed Abusive } \\
\text { Supervision X Friendship } \\
\text { Ties }\end{array}$ & & -0.01 & & $0.20^{* *}$ \\
\hline$R^{2}$ & .08 & .09 & .28 & .32 \\
\hline$\Delta R^{2}$ & & .01 & & $.04^{*}$ \\
\hline
\end{tabular}

Note. $\quad N=103 * * p \leq .01,{ }^{*} p \leq .05,{ }^{\dagger} p \leq .10$. 
Table 3: Descriptive Statistics, Reliabilities, and Correlations of Study 2 Variables

\begin{tabular}{|c|c|c|c|c|c|c|c|c|c|}
\hline Variables & $M$ & $S D$ & 1 & 2 & 3 & 4 & 5 & 6 & 7 \\
\hline 1. Gender & 1.53 & .51 & 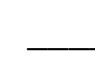 & & & & & & \\
\hline 2. Age & 30.01 & 9.34 & .00 & $\longrightarrow$ & & & & & \\
\hline 3. Observed Abusive Supervision & 1.58 & 1.01 & -.13 & -.05 & $(.96)$ & & & & \\
\hline 4. Friendship Ties & 5.78 & .89 & .15 & -.05 & -.09 & $(.89)$ & & & \\
\hline 5. Moral Courage & 5.03 & .91 & .03 & .14 & -.11 & .06 & $(.70)$ & & \\
\hline 6. Voice & 5.46 & 1.01 & .09 & .09 & $-.21 *$ & -.12 & .10 & $(.90)$ & \\
\hline 7. Standing up Behavior & 5.28 & 1.33 & -.09 & .12 & $-.24 * *$ & -.01 & .08 & $.29 * *$ & $(.88)$ \\
\hline
\end{tabular}

Note. $\quad N=122 * * p \leq .01,{ }^{*} p \leq .05,{ }^{\dagger} p \leq .10$. (2-tailed). Coefficient $\alpha$ reliabilities are reported in the diagonal. 
Table 4: Study 2 Results of Regression Analysis

\begin{tabular}{|c|c|c|c|c|c|c|}
\hline \multirow[t]{2}{*}{ Variables } & \multicolumn{3}{|c|}{ Voice } & \multicolumn{3}{|c|}{ Standing up Behavior } \\
\hline & Step 1 & Step 2 & $\underline{\text { Step } 3}$ & Step 1 & Step 2 & $\underline{\text { Step } 3}$ \\
\hline Constant & $4.37 * *$ & $4.45^{* *}$ & $4.46 * *$ & $5.11^{* *}$ & $5.26 * *$ & $5.29 * *$ \\
\hline Gender & $0.38 *$ & $0.36^{\dagger}$ & $0.34^{\dagger}$ & -0.14 & -0.22 & $-0.29^{\dagger}$ \\
\hline Age & 0.01 & 0.01 & 0.01 & 0.01 & 0.01 & 0.01 \\
\hline $\begin{array}{l}\text { Observed Abusive } \\
\text { Supervision }\end{array}$ & & $-0.18^{\dagger}$ & $-0.17^{\dagger}$ & & $-0.29 * *$ & $-0.24 * *$ \\
\hline Moral Courage & & 0.04 & 0.05 & & -0.01 & 0.04 \\
\hline Friendship Ties & & -0.11 & -0.09 & & 0.04 & 0.12 \\
\hline $\begin{array}{l}\text { Observed Abusive } \\
\text { Supervision X Moral } \\
\text { Courage }\end{array}$ & & & 0.06 & & & 0.15 \\
\hline $\begin{array}{l}\text { Observed Abusive } \\
\text { Supervision X } \\
\text { Friendship Ties }\end{array}$ & & & 0.03 & & & $0.29 * *$ \\
\hline$R^{2}$ & $.04 *$ & .08 & .08 & .01 & .12 & .19 \\
\hline$\Delta R^{2}$ & & .04 & .00 & & $.11^{* *}$ & $.07 * *$ \\
\hline
\end{tabular}

Note. $\quad N=122 * * p \leq .01,{ }^{*} p \leq .05,{ }^{\dagger} p \leq .10$ 
Table 5: Descriptive Statistics, Reliabilities, and Correlations of Study 3 Variables

\begin{tabular}{|c|c|c|c|c|c|c|c|c|c|c|c|c|}
\hline Variables & $M$ & $S D$ & 1 & 2 & 3 & 4 & 5 & 6 & 7 & 8 & 9 & 10 \\
\hline 1.Gender & 1.45 & .49 & $\underline{-}$ & & & & & & & & & \\
\hline 2. Age & 25.47 & 7.68 & $.14^{\dagger}$ & 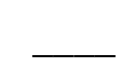 & & & & & & & & \\
\hline $\begin{array}{l}\text { 3. Abusive Supervision Toward } \\
\text { Focal Employee }\end{array}$ & 1.51 & .73 & -.05 & -.07 & $(.86)$ & & & & & & & \\
\hline 4. Observed Abusive Supervision & 1.66 & 1.03 & -.08 & .00 & $.68^{* *}$ & $(.91)$ & & & & & & \\
\hline 5. Friendship Ties & 5.58 & 1.10 & $-.19 *$ & .01 & $-.15^{\dagger}$ & .07 & $(.91)$ & & & & & \\
\hline 6. Overall Justice Climate & 5.35 & 1.32 & $-.15^{\dagger}$ & .02 & $-.37 * *$ & $-.39 * *$ & $.13^{\dagger}$ & $(.96)$ & & & & \\
\hline 7. Moral Courage & 4.81 & .81 & $.14^{\dagger}$ & $.18 *$ & $-.18 *$ & $-.15^{\dagger}$ & .01 & .02 & $(.69)$ & & & \\
\hline 8. Helping & 6.09 & .82 & $.14^{\dagger}$ & $.19 *$ & $-.14^{\dagger}$ & -.04 & $.15^{\dagger}$ & .11 & .04 & $(.91)$ & & \\
\hline 9. Voice & 5.27 & 1.11 & .07 & $.14^{\dagger}$ & .03 & -.01 & .00 & -.04 & -.05 & $.45^{* *}$ & $(.93)$ & \\
\hline 10. Standing up Behavior & 5.23 & .89 & -.01 & $.21^{* *}$ & -.08 & -.07 & .06 & .07 & .05 & $.36 * *$ & $.50 * *$ & $(.88)$ \\
\hline
\end{tabular}

Note. $\quad N=157{ }^{* *} p \leq .01,{ }^{*} p \leq .05,{ }^{\dagger} p \leq .10$. (2-tailed). Coefficient $\alpha$ reliabilities are reported in the diagonal. 
Table 6: Study 3 Results of Regression Analysis

\begin{tabular}{|c|c|c|c|c|c|c|c|c|c|}
\hline Variables & & Voice & & & Helping & & Stand & ig up Be & avior \\
\hline & $\underline{\text { Step } 1}$ & $\underline{\text { Step 2 }}$ & $\underline{\text { Step } 3}$ & $\underline{\text { Step } 1}$ & Step 2 & $\underline{\text { Step } 3}$ & $\underline{\text { Step } 1}$ & Step 2 & $\underline{\text { Step } 3}$ \\
\hline Constant & $-.72^{\dagger}$ & $-.80^{*}$ & -.94 & $-.77 * *$ & $-.87 * *$ & $-.86 * *$ & $-.57^{\dagger}$ & $-.60 *$ & $-.68^{*}$ \\
\hline Gender & .13 & .14 & .16 & .17 & $.26^{*}$ & $.26^{\dagger}$ & -.07 & -.05 & -.03 \\
\hline Age & .02 & $.02^{\dagger}$ & $.03 *$ & $.02 *$ & $.02 *$ & $.02 *$ & $.02 * *$ & $.02 * *$ & $.03^{* *}$ \\
\hline $\begin{array}{l}\text { Abusive Supervision } \\
\text { of Focal Employee }\end{array}$ & & .09 & -.07 & -.12 & -.13 & -.07 & -.12 & -.04 & -.05 \\
\hline $\begin{array}{l}\text { Observed Abusive } \\
\text { Supervision }\end{array}$ & & -.09 & .17 & & .07 & .03 & & -.06 & .05 \\
\hline Moral Courage & & -.13 & -.15 & & -.03 & -.03 & & -.01 & -.04 \\
\hline Friendship Ties & & .04 & .04 & & .11 & $.12^{\dagger}$ & & .05 & .07 \\
\hline Overall Justice Climate & & -.03 & -.02 & & .06 & .07 & & .02 & .05 \\
\hline $\begin{array}{l}\text { Observed Abusive } \\
\text { Supervision X Moral } \\
\text { Courage }\end{array}$ & & & -.06 & & & .05 & & & -.14 \\
\hline $\begin{array}{l}\text { Observed Abusive } \\
\text { Supervision X } \\
\text { Friendship Ties }\end{array}$ & & & -.04 & & & .06 & & & .12 \\
\hline $\begin{array}{l}\text { Observed Abusive } \\
\text { Supervision X Overall } \\
\text { Justice Climate }\end{array}$ & & & $.14^{*}$ & & & .00 & & & $.11 *$ \\
\hline$R^{2}$ & .02 & .04 & .07 & $.06 *$ & .10 & .11 & $.05^{*}$ & .06 & .11 \\
\hline$\Delta R^{2}$ & & .02 & .03 & & .04 & .01 & & .01 & $.05 *$ \\
\hline
\end{tabular}

Note. $\quad N=157^{* *} p \leq .01,{ }^{*} p \leq .05,{ }^{\dagger} p \leq .10$. 
APPENDIX B: FIGURES 
Figure 1: Theoretical model

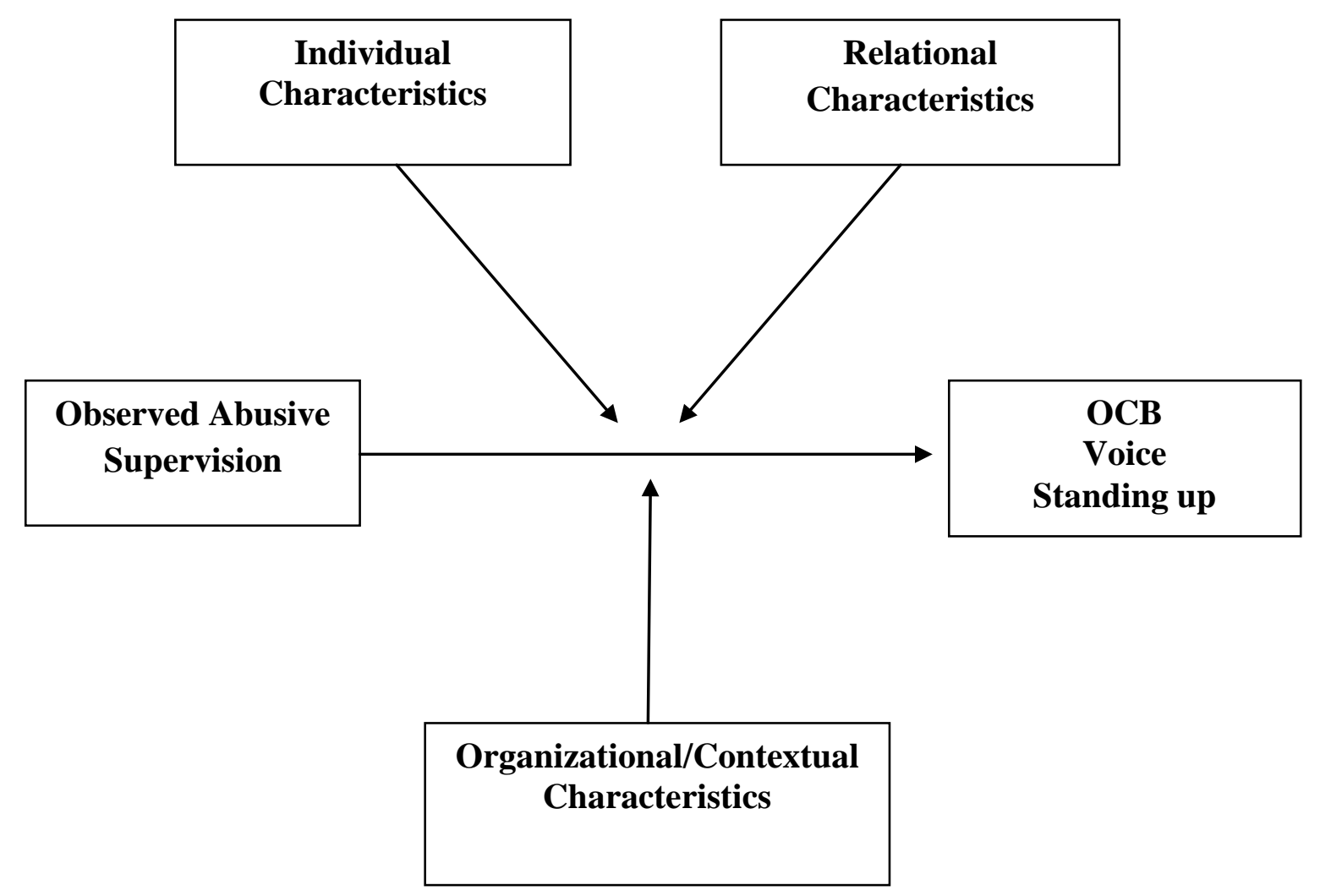


Figure 2: Study 1 Interaction between observed abusive supervision and friendship ties on standing up behavior.

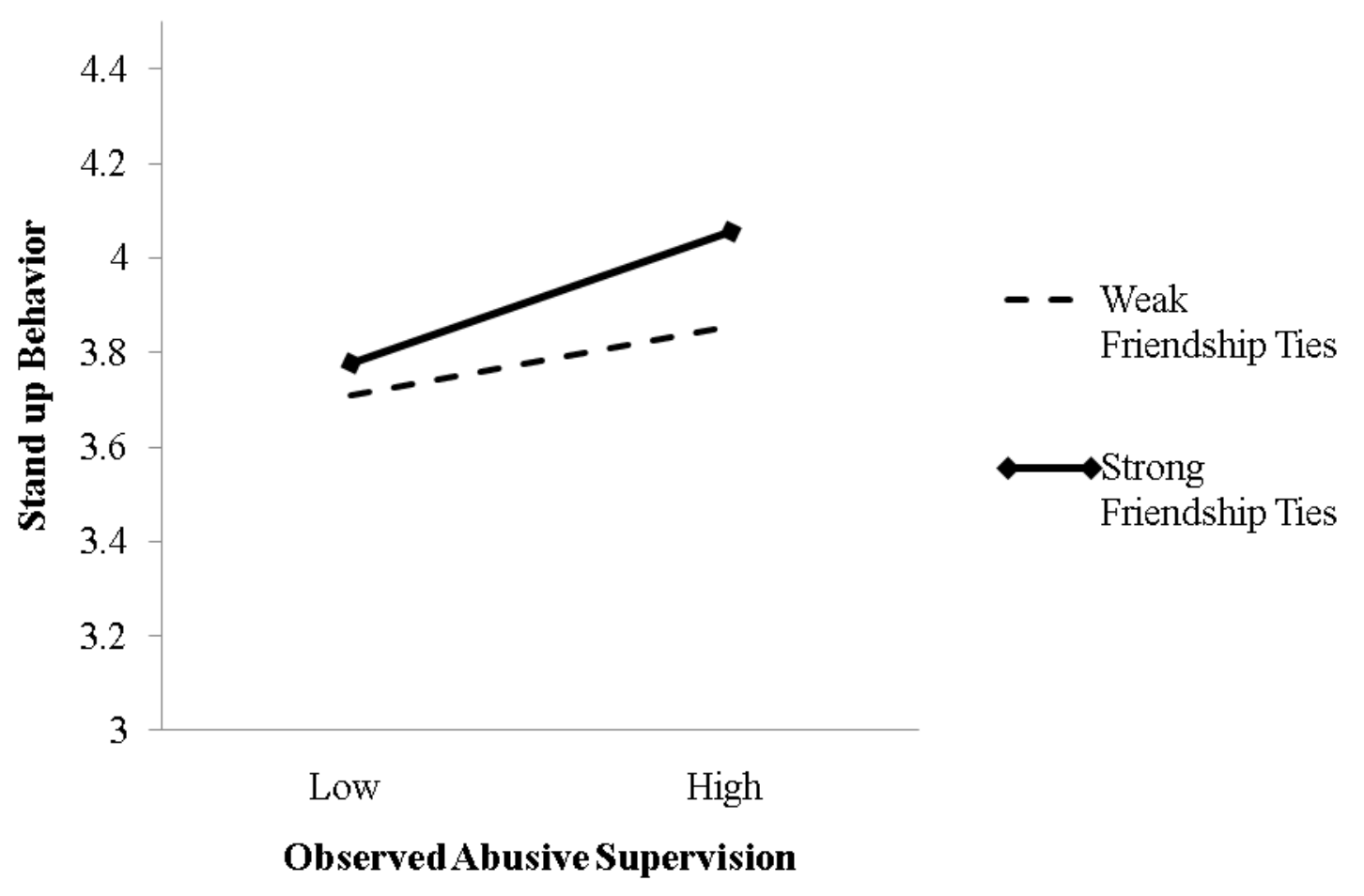


Figure 3: Study 2 Interaction between observed abusive supervision and friendship ties on standing up behavior.

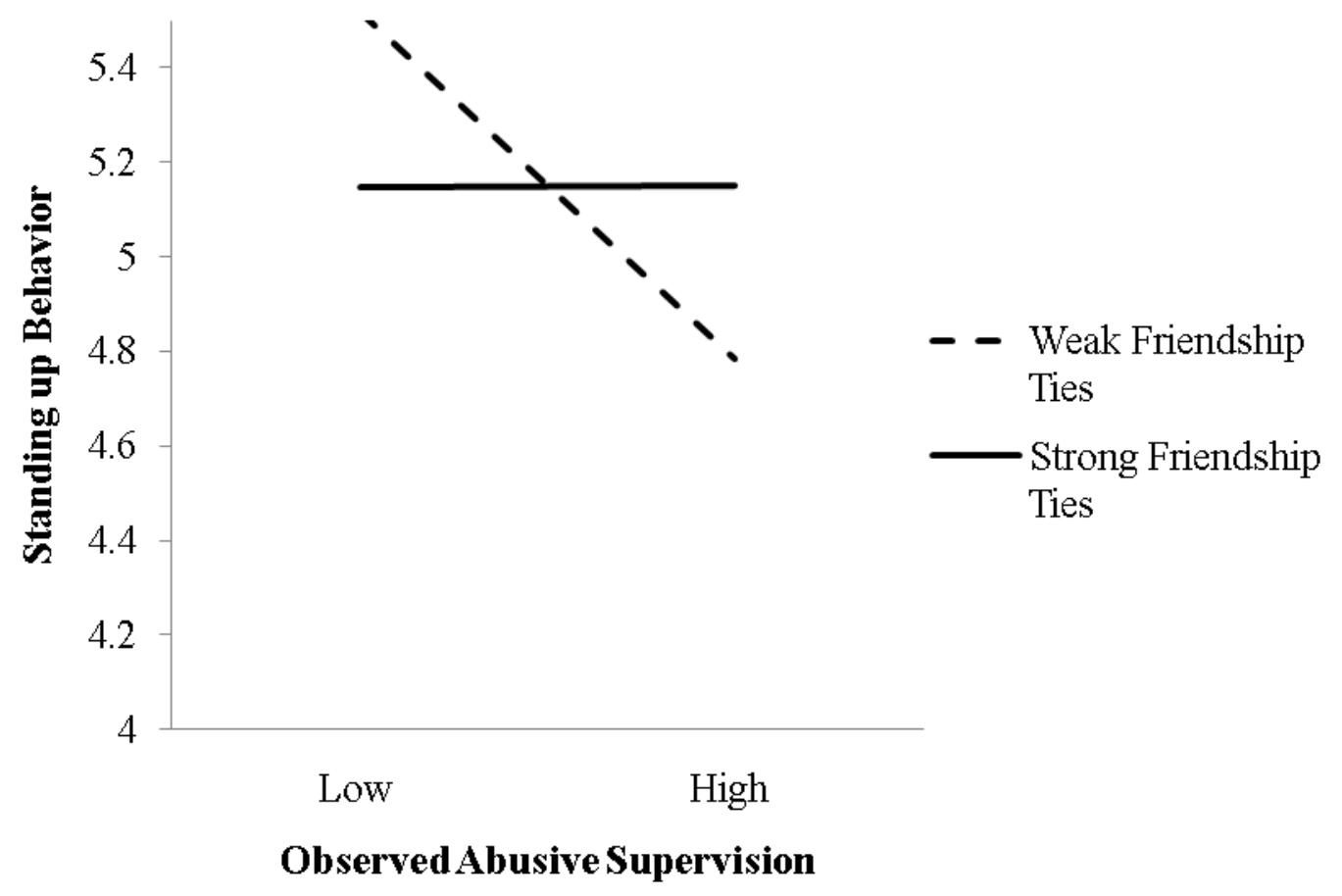


Figure 4: Study 3 Interaction between observed abusive supervision and organizational justice on standing up behavior.

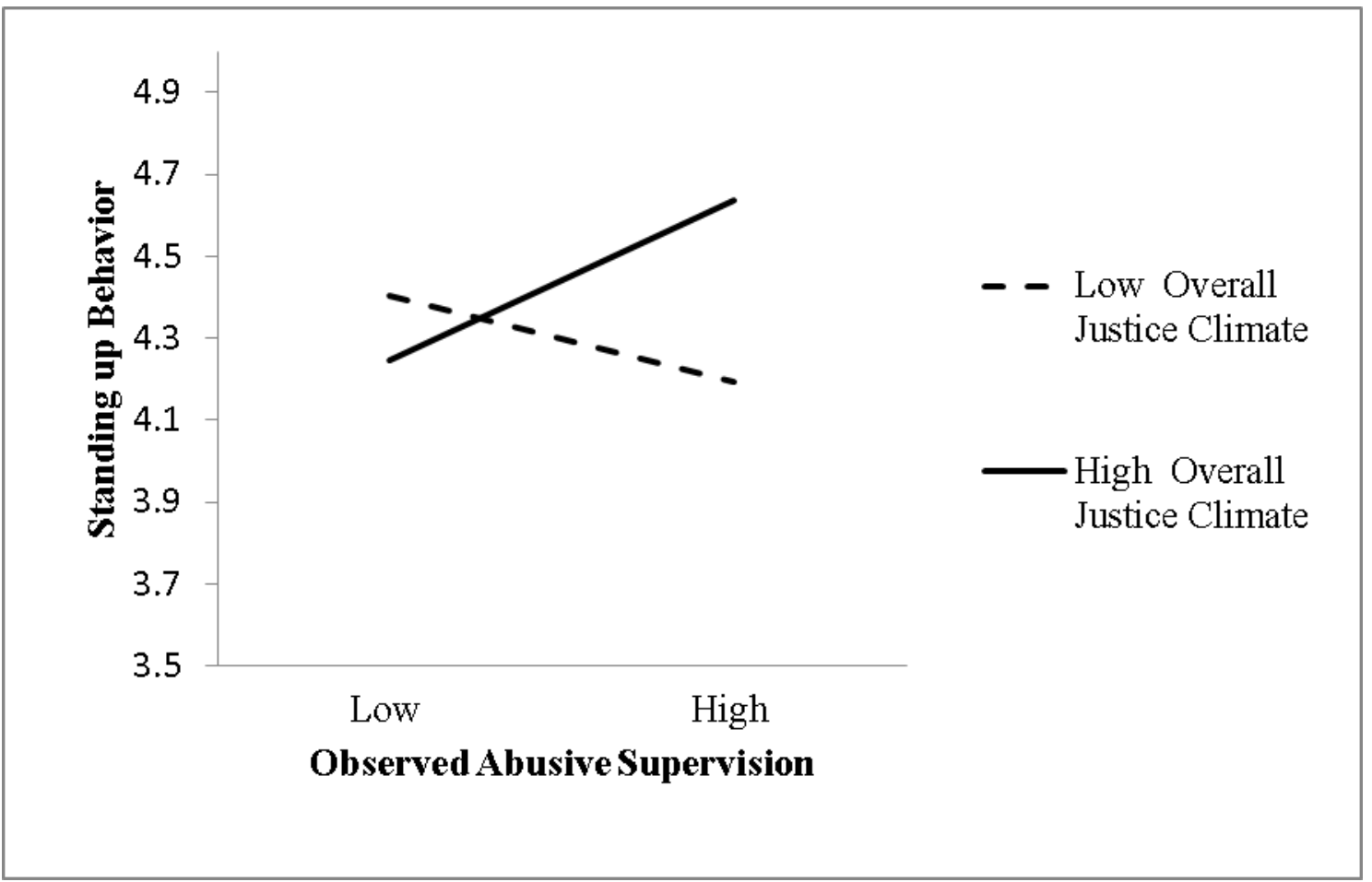


Figure 5: Study 3 Interaction between observed abusive supervision and organizational justice on voice.

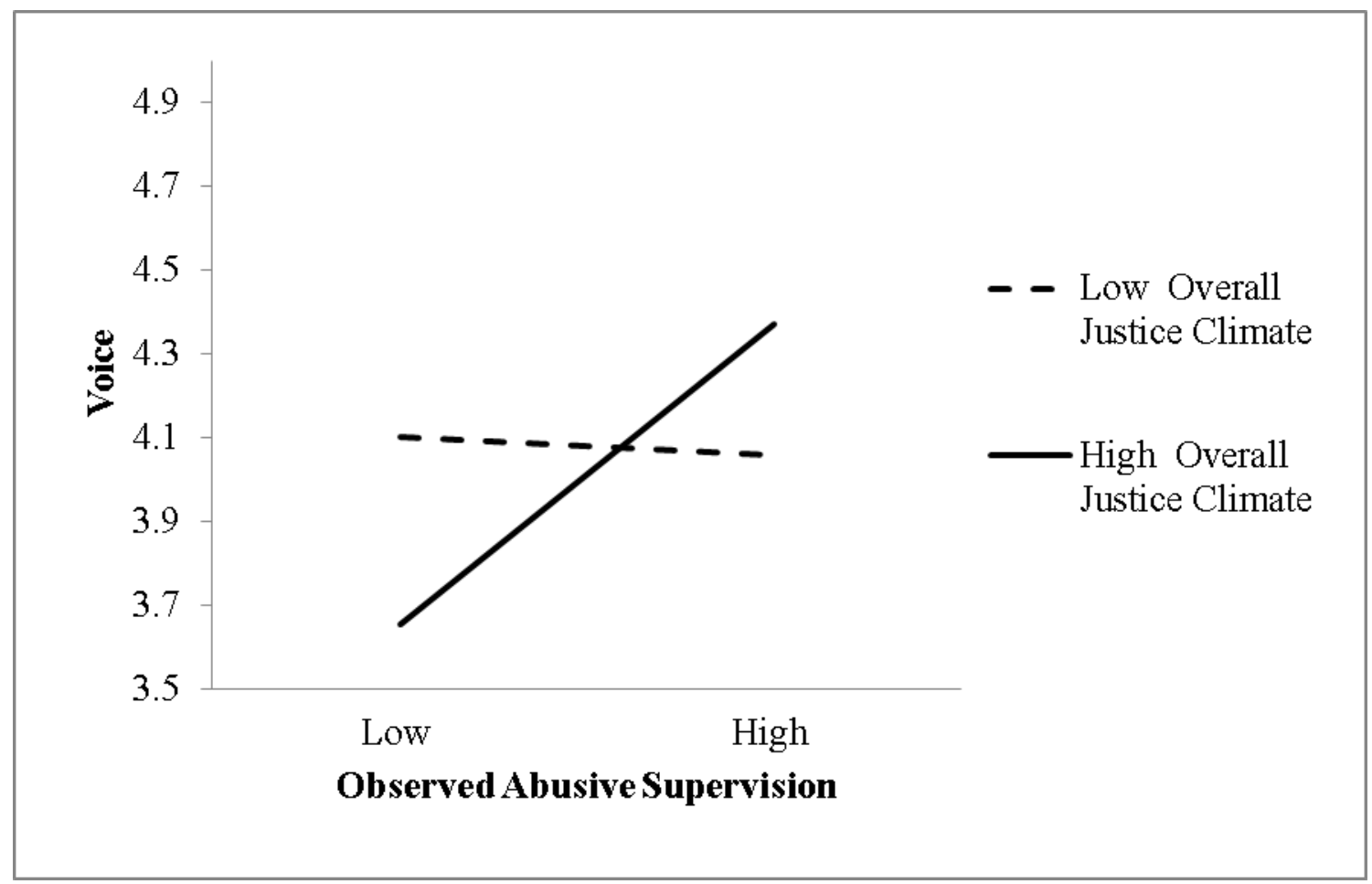


APPENDIX C: SCALES 


\section{Survey Items for Study 1}

Manipulation Check Items

1. The supervisor is abusive toward this employee.

2. The supervisor is rude and unprofessional.

3. The employee that is treated unfairly is a good friend of yours.

4. You have a close relationship with the unfairly treated employee.

Moral Courage (Sekerka, Bagozzi, \& Charnigo, 2009)

1. When I encounter an ethical challenge I take it on with moral action, regardless of how it may pose a negative impact on how others see me.

2. When my job record may be affected negatively, I am unlikely to get involved with an ethical challenge.

3. I am the type of person who wants to keep things subdued, not raise issues, or put myself or others in jeopardy by bringing a moral issue forward.

4. I hold my ground on moral matters, even if there are opposing social pressures.

5. I act morally even if it puts me in an uncomfortable position with my superiors.

6. I am swayed from acting morally by fear or other negative feelings.

Standing up Behavior (adapted from Sekerka, Bagozzi, \& Charnigo, 2009)

1. I am willing to stand up for the employee even though it may put me in an uncomfortable situation with my superiors.

2. I am willing to face this ethical dilemma and help out even though I may be at risk.

3. I am going to act on my moral principles and stand up for the unfairly treated employee.

4. I am willing to stand up for the employee even if I encounter negative consequences.

5. Regardless of the risk, I will help and support the employee.

6. I am willing to stand up for the unfairly treated person.

Voice (adapted from LePine \& van Dyne, 1998)

1. I develop and make recommendations to improve the situation between the supervisor and employees.

2. I speak up and encourage others in the work group to get involved in issues that affect the employees.

3. I communicate my opinions about unethical situations to others in the work group even if his/her opinion is different and others in the group disagree with me.

4. I get involved in issues that might affect the quality of work life in the work group.

5. I speak up in this department about unethical issues such as abuse of employees.

6. I keep myself well informed about issues and concerns in the work group. 
Survey Items for the Field Studies (Studies 2 and 3)

Abusive Supervision Rated by Observer (Control Variable)

(Mitchell \& Ambrose, 2007 adapted from Tepper, 2000)

1. Ridicules me.

2. Tells me my thoughts or feelings are stupid.

3. Puts me down in front of others.

4. Makes negative comments about me to others.

5. Tells me that I am incompetent.

Observed Abusive Supervision Rated by Observer

(Mitchell \& Ambrose, 2007 adapted from Tepper, 2000)

1. Ridicules my coworker.

2. Tells my coworker that his/her thoughts or feelings are stupid.

3. Puts my coworker down in front of others.

4. Makes negative comments about my coworker to others.

5. Tells my coworker that he/she is incompetent.

Friendship Ties Rated by Observer

(Adapted from Petróczi, Nepusz, and Bazsó, 2007).

1. I like my coworker.

2. I trust my coworker (for example he/she knows your name, email address, password to your computer or email or phone)

3. Your coworker would ask for your help or a favor.

4. You would ask your coworker for help or a favor.

5. I have private correspondence with my coworker.

6. I consider my coworker a friend.

7. My coworker and I talk about topics other than work.

8. I would like to have a discussion about other topics with my coworker.

9. I like spending time with my coworker.

Overall Justice Climate Rated by Observer

(Ambrose \& Schminke, 2009)

1. Overall, people in the department are treated fairly by my organization.

2. Usually, the way things work in this organization is fair.

3. In general, people can count on this organization to be fair.

4. For the most part, this organization treats its employees fairly. 
5. In general, the treatment people receive around here is fair.

6. Most of the people who work here would say that they are mostly treated fairly.

\section{Moral Courage Rated by Observer}

(adapted from Sekerka, Bagozzi, \& Charnigo, 2009)

1. When I encounter an ethical challenge I am the kind of person who takes it on with moral action, regardless of how it may pose a negative impact on how others see me.

2. When my job record may be affected negatively, I am the type of person who is unlikely to get involved with an ethical challenge.

3. I am the type of person who wants to keep things subdued, not raise issues, or put myself or others in jeopardy by bringing a moral issue forward.

4. Others describe me as a person who holds his/her ground on moral matters, even if there are opposing social pressures.

5. I see myself as a person who acts morally even if it puts me in an uncomfortable position with my superiors.

6. I am the kind of person who is easily swayed from acting morally by fear or other negative feelings.

Helping Behavior Rated by Supervisor

(adapted from Podsakoff, MacKenzie, Moorman \& Fetter, 1990)

The employee who asked me to fill out this survey...

1. helps this coworker when this coworker has heavy workloads.

2. is always ready to lend a helping hand to this coworker.

3. helps this coworker when he/she has been absent.

4. willingly helps this coworker when the coworker has work-related problems.

5. would help orient this coworker even though it was not required.

Voice Behavior Rated by Supervisor

(adapted from van Dyne \& LePine, 1998)

The employee who asked me to fill out this survey...

1. develops and makes recommendations concerning issues that affect this coworker.

2. speaks up and encourages others in the group to get involved in issues that affect this coworker.

3. communicates opinions about issues concerning this coworker to others in the group even if their opinion is different and others in the group disagree with him/her.

4. gets involved in issues that might affect the quality of this coworker's work life.

5. speaks up about issues and behaviors that would affect this coworker.

6. keeps well informed about issues where his/her opinion might be useful to this coworker. 
Standing up Behavior Rated by Supervisor

The employee who asked me to fill out this survey...

1. would approach me about my behavior even if it may put him/her in an uncomfortable position.

2. would confront me even if he/she might encounter negative consequences.

3. would face up to me regardless of the risk involved.

4. would be willing to meet with me and talk about my actions, regardless of any potential negative consequences.

5. would stand up for his/her coworker.

6. would side with his/her coworker.

7. would defend his/her coworker against me.

8. would take his/her coworker's side.

9. would support his/her coworker. 


\section{REFERENCES}

Adams, J.S. (1965). Inequity in social exchange. Advances in Experimental Social Psychology. 62, 335-343.

Aiken, L. S., \& West, S. G. (1991). Multiple regression: Testing and interpreting interactions. Newbury Park, CA: Sage.

Allen, V. L., \& Greenberger, D. B. (1980). Destruction and perceived control. In A. Braun \& J. E. Singe (Eds.), Advances in Environmental Psychology (pp. 85-109). Hillsdale: Erlbaum.

Ambrose, M. L., \& Schminke, M. (2009). The role of overall justice judgments in organizational justice research: A test of mediation. Journal of Applied Psychology, 94, 491-500.

Anderson, C. A., \& Bushman, B. J. (2002). Human aggression. Annual Review of Psychology, 53, 27-51.

Aryee, S., Chen, Z. X., Sun, L., \& Debrah, Y. A. (2007). Antecedents and outcomes of abusive supervision: Test of a trickle-down model. Journal of Applied Psychology, 92, 191-201.

Aryee, S., Sun, L., Chen, Z. X., \& Debrah, Y.A. (2008). Abusive supervision and contextual performance: The mediating role of emotional exhaustion and the moderating role of work unit structure. Management and Organization Review, 4, 393-411.

Ashforth, B. (1997). Petty tyranny in organizations: A preliminary examination of antecedents and consequences. Canadian Journal of Administrative Sciences, 14, 126-140.

Ashforth, B. (2003). Petty tyranny in organizations. In L. W. Porter, H. L. Angle, \& P. W. Allen (Eds.), Organizational influence processes (pp. 151-171). Armonk, NY: M. E. Sharpe. 100 
Bagozzi, R. P., \& Edwards, J. R. (1998). A general approach for representing constructs in organizational research. Organizational Research Methods, 1, 45-87.

Bamberger, P.A., \& Bacharach, S.B. (2006). Abusive supervision and subordinate problem drinking: Taking resistance, stress and subordinate personality into account. Human Relations, 59, 723-752.

Baumeister, R.F., Stillwell, A.M., \& Heatherton, T.F. (1994). Guilt: An interpersonal approach. Psychological Bulletin, 115, 243-267.

Becker, T. E. (2005). Potential problems in the statistical control of variables in organizational research: A qualitative analysis with recommendations. Organizational Research Methods, 8, 274-289.

Bies, R.J., \& Moag, J.S. (1986). Interactional justice: Communication criteria of fairness. Research on Negotiation in Organizations, 1, 43-55.

Bies, R.J. (2000). Interactional (in)justice: The sacred and the profane. In J. Greenberg \& R. Cropanzano (Eds.), Advances in organizational behavior (pp.89-109). Stanford, CA: Stanford University Press.

Biron, M. (2010). Negative reciprocity and the association between perceived organizational ethical values and organizational deviance. Human Relations, 63, 975-897.

Blau, P. (1964). Exchange and power in social life. New York: Wiley.

Bowes-Sperry, L., \& O'Leary-Kelly, A.M. (2005). To act or not to act: The dilemma faced by sexual harassment observers. Academy of Management Review, 30, 288-306.

Brown, S.P., \& Leigh, T.W. (1996). A new look at psychological climate and its relationship to job involvement, effort, and performance. Journal of Applied Psychology, 81, 358-368. 
Burris, E.R., Detert, J.R., \& Chiaburu, D.S. (2008). Quitting before leaving: The mediating effects of psychological attachment and detachment on voice. Journal of Applied Psychology, 93, 912-922.

Cialdini, R. B., Brown, S. L., Lewis, B. P., Luce, C., \& Neuberg, S. L. (1997). Reinterpreting the empathy-altruism relationship: When one into one equals oneness. Journal of Personality and Social Psychology, 73, 481-494.

Cohen, J., Cohen, P., West, S. G., \& Aiken, L. S. (2003). Applied multiple regression/correlation analysis for the behavioral sciences (3rd ed.). Mahwah, NJ: Erlbaum.

Colquitt, J. A. (2001). On the dimensionality of organizational justice: A construct validation of a measure. Journal of Applied Psychology, 86, 386-400.

Colquitt, J. A., Conlon, D. E., Wesson, M. J., Porter, C. O. L. H., \& Ng, K. Y. (2001). Justice at the millennium: A meta-analytic review of 25 years of organizational justice research. Journal of Applied Psychology, 86, 425-445.

Colquitt, J. A., \& Shaw, J. C. (2005). Measuring organizational justice. In J. Greenberg \& J. A. Colquitt (Eds.), The handbook of organizational justice (pp. 113-152). Mahwah, NJ: Erlbaum.

Cropanzano, R., Goldman, B. M., \& Folger, R. (2003). Deontic justice: The role of moral principles in workplace fairness. Journal of Organizational Behavior, 24, 1019-1024.

Cropanzano, R., Goldman, B. M., \& Folger, R. (2005). What is self-interest? Journal of Organizational Behavior, 26, 985-991. 
Crossley, C.D. (2009). Emotional and behavioral reactions to social undermining: A closer look at perceived offender motives. Organizational Behavior and Human Decision Processes, $108,14-24$.

D’Cruz, P., \& Noronha, E. (2010). The exit coping response to workplace bullying: The contribution of inclusivist and exclusivist HRM strategies. Employee Relations, 32, 102120.

Detert, J.R., \& Burris, E.R. (2007). Leadership behavior and employee voice: Is the door really open? Academy of Management Journal, 50, 869-884.

Detert, J. R., Treviño, L. K., Burris, E. R., \& Andiappan, M. (2007). Managerial modes of influence and counterproductivity in organizations: A longitudinal business-unit-level investigation. Journal of Applied Psychology, 92, 993-1005.

Dietz, J., Robinson, S.L., Folger, R., Baron, R.A., \& Schulz, M. (2003). The impact of community violence and an organization’s procedural justice climate on workplace aggression. Academy of Management Journal, 46, 317-326.

Douglas, S.C., \& Martinko, M.J. (2001). Exploring the role of individual differences in the prediction of workplace aggression. Journal of Applied Psychology, 86, 547-559.

Duffy, M.K., Ganster, D.C., \& Pagon, M. (2002). Social undermining in the workplace. Academy of Management Journal, 45, 331-351.

Duffy, M.K., Ganster, D.C., Shaw, J.D., Johnson, J. L., \& Pagon, M (2006). The social context of undermining at work. Organizational Behavior and Human Decision Processes, 101, 104-126. 
Dupre, K.E., \& Barling, J. (2006). Predicting and preventing supervisory workplace aggression. Journal of Occupational Health Psychology, 11, 13-26.

Einarsen, S., \& Mikkelsen, E. (2003). Individual effects of exposure to bullying at work. In S. Einarsen, H. Hoel, D. Zapf, \& C. Cooper (Eds.), Bullying and emotional abuse in the workplace: International perspectives in research and practice (pp. 127-144). London: Taylor \& Francis.

Emerson, R. M. (1972). Exchange theory, Part I: A psychological basis for social exchange. In J. Berger, M. Zelditch, \& B. Anderson (Eds.), Sociological theories in progress (pp. 3857). Boston, MA: Houghton-Mifflin.

Fischer, P., Greitemeyer, T., Pollozek, F., \& Frey, D. (2006). The unresponsive bystander: Are bystander more responsive in dangerous emergencies. European Journal of Social Psychology, 36, 267-278.

Folger, R. (1998). Fairness as a moral virtue. In M. Schminke (Ed.), Managerial ethics: Morally managing people and processes (pp. 13-34). Mahwah, NJ: Lawrence Erlbaum Associates.

Folger, R. (2001). Fairness as deonance. In S. W. Gilliland, D. D. Steiner, \& D. P. Skarlicki (Eds.), Research in Social Issues in Management (pp. 3-31). Greenwich, CT: Information Age Publishing.

Folger, R., \& Cropanzano, R. (2010). Social hierarchies and the evolution of moral emotions. In M. Schminke (Ed.), Managerial ethics: Moral management of people and processes (2nd ed.) (pp. 207-229). New York, NY: Psychology Press/Routledge. 
Grandey, A. A., Kern, J., \& Frone, M. (2007). Verbal abuse from outsiders versus insiders: Comparing frequency, impact on emotional exhaustion, and the role of emotional labor. Journal of Occupational Health Psychology, 12, 63-79.

Grant, C. (2002). Whistle blowers: Saints of secular culture. Journal of Business Ethics, 39, 391- 400.

Grant, A. M., \& Mayer, D. M. (2009). Good soldiers and good actors: Prosocial and impression management motives as interactive predictors of affiliative citizenship behaviors. Journal of Applied Psychology, 94, 900-912.

Greenbaum, R. L., Bardes, M., Mayer, D. M., \& Priesemuth, M. (2009). Supervisors’abuse of customers: The moderating role of moral obligation. Paper presented at the annual meeting of the Academy of Management, Chicago.

Greenbaum, R. L., Bardes, M., Mayer, D. M., \& Priesemuth, M. (2011). Supervisors’abuse of customers: The moderating role of moral identity. Paper presented at the annual meeting of the Academy of Management, San Antonio.

Greenberg, J. (1990). Employee theft as a reaction to underpayment inequity: The hidden cost of pay cuts. Journal of Applied Psychology, 75, 561-568.

Greenberg, J. (1993). Stealing in the name of justice: Informational and interpersonal moderators of theft reactions to underpayment inequity. Organizational Behavior and Human Decision Processes 54, 81-103.

Gulati, R., Dialdin, D., \& Wang, L. (2002). Organizational networks. In J. Baum (Ed.), Companion to organizations (pp. 520-540). Malden: Blackwell. 
Harris, K. J., Kacmar, K. M., \& Zivnuska, S. (2007). An investigation of abusive supervision as a predictor of performance and the meaning of work as a moderator of the relationship. The Leadership Quarterly, 18, 252-263.

Harvey, P., Stoner, J., Hochwarter, W., \& Kacmar, C. (2007). Coping with abusive supervisors: The neutralizing effects of ingratiation and positive affect on negative employee outcomes. The Leadership Quarterly, 18, 264-280.

Hershcovis, S. M., Turner, N., Barling, J., Arnold, K. A., Dupre, K. E., Inness, M., LeBlanc, M. M., \& Sirvanathan, N. (2007). Predicting workplace aggression: A meta-analysis. Journal of Applied Psychology, 92, 228-238.

Hershcovis, M.S., \& Barling, J. (2010). Comparing victim attributions and outcomes for workplace aggression and sexual harassment. Journal of Applied Psychology, 95, 874888.

Hershcovis, M.S. (2011). Incivility, social undermining, bullying....oh my! A call to reconcile constructs within workplace aggression research. Journal of Organizational Behavior, 32, 499-519.

Hobfoll, S. E. (1989). Conservation of resources: A new attempt at conceptualizing stress. The American Psychologist, 44, 513-524.

Hobman, E. V., Restubog, S. L. D., Bordia, P., \& Tang, R. L. (2009). Abusive supervision in advising relationships: Investigating the role of social support. Applied Psychology: An International Review, 58, 233-256. 
Hoel, H., Rayner, C., \& Cooper, C. L. (1999). Workplace bullying. In C. L. Cooper \& I. T. Robertson (Eds.), International review of industrial and organizational psychology (pp. 195-230). London: Wiley.

Hogg, M. A. (1987). Social identity and group cohesiveness. In J. C. Turner, M. A. Hogg, P. J. Oakes, S. D. Reicher, \& M. S. Wetherell (Eds.), Rediscovering the social group: A selfcategorization theory (pp. 89-116). Oxford: Blackwell.

Hogg, M.A., \& Hains, S. C. (1998). Friendship and group identification: A new look at the role of cohesiveness in groupthink. European Journal of Social Psychology, 28, 323-341.

Hogg, M. A., \& Terry, D. J. (2000). Social identity and self-categorization processes in organizational contexts. Academy of Management Review, 25, 121-140.

Holtz, B. C., \& Harold, C. M. (2009). Fair today, fair tomorrow? A longitudinal investigation of overall justice perceptions. Journal of Applied Psychology, 94, 1185-1199.

Hoobler, J., \& Brass, D. (2006). Abusive supervision and family undermining as displaced aggression. Journal of Applied Psychology, 91, 1125-1133.

Hoyle, R. H., \& Panter, A. T. (1995). Writing about structural equation models. In R. H. Hoyle (Ed.), Structural equation modeling: Concepts, issues, and applications (pp.158-176). Thousand Oaks, CA: Sage.

Inness, M., Barling, J., \& Turner, N. (2005). Understanding supervisor-targeted aggression: A within-person, between-jobs design. Journal of Applied Psychology, 90, 731-739.

James, L. A., Choi, C. C., Ko, C. E., McNeil, P. K., Minton, M. K., Wright, M. A., \& Kim, K. (2008). Organizational and psychological climate: A review of the theory and research. European Journal of Work and Organizational Psychology, 17, 5-32. 
James L. R., \& Jones, A.P. (1974). Organizational climate: A review of theory and research. Psychological Bulletin, 81, 1096-1112.

Jones, D. A. (2009). Getting even with one’s supervisor and one’s organization: Relationships among types of injustice, desires for revenge, and counterproductive work behaviors. Journal of Organizational Behavior, 30, 525-542.

Jones, D. A., \& Martens, M. L. (2009). The mediating role of overall fairness and the moderating role of trust certainty in justice-criteria relationships: The formation and use of fairness heuristics in the workplace. Journal of Organizational Behavior, 30, 1025-1051.

Jöreskog, K. G., \& Sörbom, D. (2006). LISREL for windows. Lincolnwood, IL: Scientific Software International, Inc.

Jubb, P.B. (1999). Whistleblowing: A restrictive definition and interpretation. Journal of Business Ethics, 21, 77-94.

Judge, T. A., Scott, B. A., \& Ilies, R. (2006). Hostility, job attitudes, and workplace deviance: Test of a multilevel model. Journal of Applied Psychology, 91, 126-138.

Kahneman, D., Knetsch, J. L., \& Thaler, R. (1986). Fairness as a constraint on profit seeking: Entitlements in the market. American Economic Review, 76, 728-741.

Kidder, R.M., \& Bracy, M. (2001). Moral courage: A white paper. Camden, Maine: Institute for Global Ethics.

Kogut, T., \& Ritov, I. (2007). “One of us”: Outstanding willingness to help save a single identified compatriot. Organizational Behavior and Human Decision Processes, 104, 150-157. 
Kuenzi, M., \& Schminke, M. (2009). Assembling fragments into a lens: A review, critique, and proposed research agenda for the organizational work climate literature. Journal of Management, 35, 634-717.

Landis, R., Beal, D., \& Tesluk, P. E. (2000). A comparison of approaches to forming composite measures in structural equation models. Organizational Research Methods, 3, 186-207.

Lawrence, T. B., \& Robinson, S. L. (2007). Ain't misbehaving: Workplace deviance as organizational resistance. Journal of Management, 33, 378-394.

Lazarus, R.S., \& Folkman, S. (1984). Stress, appraisal and coping. New York: Springer.

Leventhal, G. S. (1980). What should be done with equity theory?. In K. J. Gergen, M. S. Greenberg, \& R. H. Willis (Eds.), Social Exchange: Advances in Theory and Research (pp. 27-55). New York: Plenum.

Levine, M., Cassidy, C., Brazier, G., \& Reicher, S. (2002). Self-categorization and bystander non-intervention: Two experimental studies. Journal of Applied Social Psychology, 32, $1452-1463$.

Levine, M., Prosser, A., Evans, D., \& Reicher, S. (2005). Identity and emergency intervention: How social group membership and inclusiveness of group boundaries shapes helping behavior. Personality and Social Psychology Bulletin, 31, 443-453.

Levine, M., \& Crowther, S. (2008). The responsive bystander: How social group membership and group size can encourage as well as inhibit bystander intervention. Journal of Personality and Social Psychology, 95, 1429-1439. 
Liao, H., \& Rupp, D. E. (2005). The impact of justice climate and justice orientation on work outcomes: A cross-level multifoci framework. Journal of Applied Psychology, 90, 242256.

Lin, S.-P., Tang, T.-W., Li, C.-H., Wu, C.-M., \& Lin, H.-H. (2007). Mediating effect of cooperative norm in predicting organizational citizenship behaviors from procedural justice climate. Psychological Reports, 101, 67-78.

Lind, E. A. (2001). Fairness heuristic theory: Justice judgments as pivotal cognitions in organizational relations. In J. Greenberg \& R. Cropanzano (Eds.), Advances in organizational justice (pp. 56-88). Stanford, CA: Stanford University Press.

Lind, E. A., \& Van den Bos, K. (2002). When fairness works: Toward a general theory of uncertainty management. In Staw, B. M. \& Kramer, R. M. (Eds.), Research in organizational behavior (pp. 181-223). Greenwich: JAI Press, CT.

Lodewijkx, H. F. M., Kersten, G. L. E., \& Van Zomeren, M. (2008). Dual pathways to engage in silent marches against violence: Moral outrage, moral cleansing and modes of identification. Journal of Community and Applied Social Psychology, 18, 153-167.

Maner, J. K., Luce, C. L., Neuberg, S. L., Cialdini, R. B., Brown, S., \& Sagarin, B. J. (2002). The effects of perspective taking on motivations for helping: Still no evidence for altruism. Personality and Social Psychology Bulletin, 28, 1601-1610.

Mathisen, G. E., Einarsen, S., \& Mykletun, R. (2011). The relationship between supervisor personality, supervisors’ perceived stress and work place bullying. Journal of Business Ethics, 99, 637-651. 
Mayer, D. M., Kuenzi, M., Greenbaum, R., Bardes, M., \& Salvador, R. (2009). How low does ethical leadership flow? Test of a trickle-down model. Organizational Behavior and Human Decision Processes, 108, 1-13.

Mayer, D.M., Greenbaum, R.L., Kuenzi, M., \& Shteynberg, G. (2009). When Do Fair Procedures Not Matter? A Test of the Identity Violation Effect. Journal of Applied Psychology, 94, 142-161.

Miller, N. E. (1941). The frustration-aggression hypothesis. Psychological Review, 48, 337-342.

Miller, R. (2005). Moral courage: Definition and development. Washington, DC: Ethics Resource Center.

Mischel, W. (1973). Toward a cognitive social learning reconceptualization of personality. Psychological Review, 80, 252-253.

Mitchell, M. S., \& Ambrose, M. L. (2007). Abusive supervision and workplace deviance and the moderating effects of negative reciprocity beliefs. Journal of Applied Psychology, 92, 1159-1168.

Mitchell, M.E., Priesemuth, M., Schminke, M., \& Vogel, R. (2011). An examination of the relationship between supervisor abuse and subordinate deviance and the moderating effects of work environment structure. Paper presented at the annual meeting of the Academy of Management, San Antonio, TX.

Mitchell, M. S., Folger, R., \& Vogel, R. M. (2012). Beyond the consequences to the victim: The impact of abusive supervision to third-party observers. In R. A. Giacalone \& M. D. Promislo (Eds.), Handbook of unethical work behavior: Implications for well-being. M. E. Sharpe. 
Mossholder, K.W., Bennett, N., \& Martin, C.L (1998). Relationships between procedural justice and affective work reactions: A multilevel analysis. Journal of Organizational Behavior, 19, 31-141.

Naumann, S. E., \& Bennett, N. (2000). A case for procedural justice climate: Development and test of a multilevel model. Academy of Management Journal, 43, 881-889.

Neiderland, W.G. (1981). The survivor syndrome: Further observations and dimensions. Journal of American Psychoanalytic Association, 29, 413-425.

Neuberg, S. L., Cialdini, R. B., Brown, S. L., Luce, C., Sagarin, B. J., \& Lewis, B. P. (1997). Does empathy lead to anything more than superficial helping? Comment on Batson et al. (1997). Journal of Personality and Social Psychology, 73, 510-516.

Neuman, J. H., \& Baron, R. A. (1998). Workplace violence and workplace aggression: Evidence concerning specific forms, potential causes, and preferred targets. Journal of Management, 24, 391-419.

Niehoff, B. P., Paul, R. J., \& Bunch, J. F. S. (1998). The social effects of punishment events: The influence of violator past performance record and severity of the punishment on observers’ justice perceptions and attitudes. Journal of Organizational Behavior, 19, 589602.

Nielsen, M.B., Matthiesen, S.B., \& Einarsen, S. (2008). Sense of coherence as a protective mechanism among targets of workplace bullying. Journal of Occupational Health Psychology, 13, 128-136. 
Niesta Kayser, D., Greitemeyer, T., Fischer, P., \& Frey, D. (2010). Why mood affects help giving but not moral courage: Two types of prosocial behaviours. European Journal of Social Psychology, 40, 1136-1157.

O'Connor, L. E., Berry, J. W., Weiss, J., Bush, M., \& Sampson, H. (1997). Interpersonal guilt: The development of a new measure. Journal of Clinical Psychology, 53, 73-89.

O' Reilly, J., \& Aquino, K. (2011). A model of third parties' morally-motivated responses to injustice. Academy of Management Review, 36, 526-543.

Parker, C. P., Baltes, B. B., Young, S. A., Huff, J. W., Altmann, R. A., Lacost, H. A., \& Roberts, J. E. (2003). Relationships between psychological climate perceptions and work outcomes: A meta-analytic review. Journal of Organizational Behavior, 24, 389-416.

Parzefall, M. R., \& Salin, D. (2010). Perceptions of and reactions to workplace bullying: A social exchange perspective. Human Relations, 63, 761-780.

Petróczi, A., Nepusz, T., \& Bazsó, F. (2007). Measuring tie-strength in virtual social networks. Connections, 27, 39-52.

Piccolo, R. F., Greenbaum, R., Den Hartog, D. N., \& Folger, R. (2010). The relationship between ethical leadership and core job characteristics. Journal of Organizational Behavior, 31, 259-278.

Podsakoff, P. M., MacKenzie, S. B., Moorman, R. H., \& Fetter, R. (1990). Transformational leader behaviors and their effects on followers' trust in leader, satisfaction, and organizational citizenship behaviors. The Leadership Quarterly, 1, 107-142. 
Podsakoff, P. M., MacKenzie, S. B., Lee, J.-Y., \& Podsakoff, N. P. (2003). Common method biases in behavioral research: A critical review of the literature and recommended remedies. Journal of Applied Psychology, 88, 879-903.

Porath, C., \& Erez, A. (2007). Does rudeness matter? The Effect of rudeness on task performance and helpfulness. Academy of Management Journal, 50, 1181-1197.

Porter, C.O. L.H., Hollenbeck, J.R., Ilgen, D.R., Ellis, A.P.J., West, B.J., \& Moon, H.K. (2003). Towards understanding backing up behaviors in work teams: The role of personality and the legitimacy of need for backing up others. Journal of Applied Psychology, 88, 391403.

Rawlings, E.I. (1968). Witnessing harm to other: A reassessment of the role of guilt in altruistic behavior. Journal of Personality and Social Psychology, 10, 377-380.

Rayner, C., \& Keashly, L. (2005). Bullying at work: A perspective from Britain and North America. In S. Fox \& P.E. Spector (Eds.) Counterproductive work behavior: Investigations of actors and targets (pp. 271-296). Washington, DC: American Psychological Association.

Restubog, S.D.L., Scott, K.D., \& Zagenczyk, T.J. (2011). When anger hits home: The role of aggressive culture in predicting abusive supervision and the effects on employees and their significant others. Journal of Applied Psychology, 96, 713-729.

Roberson, Q. M. (2006). Justice in teams: The activation and role of sensemaking in the emergence of justice climates. Organizational Behavior and Human Decision Processes, 100, 177-192. 
Robinson, S.L., \& Greenberg, J. (1998). Employees behaving badly: Dimensions, determinants, and dilemmas in the study of workplace deviance. In C.L. Cooper \& D.M. Rousseau (Eds), Trends in organizational behavior (pp. 1-30). New York: Wiley.

Robinson, S.L., \& O’Leary-Kelly, A.M. (1998). Monkey see, monkey do: The influence of work groups on the antisocial behavior of employees. Academy of Management Journal, 41, 658-672.

Rost (1991). Leadership for the $21^{\text {st }}$ Century. New York: Praeger.

Rupp, D. E., \& Bell, C. M. (2010). Extending the deontic model of justice: Moral self-regulation in third-party responses to injustice. Business Ethics Quarterly, 20, 89-106.

Rupp, D. E., \& Paddock, E. L. (2010). From justice events to justice climate: A multilevel temporal model of information aggregation and judgment. In B. Mannix, M. Neal, \& E. Mullen (Eds.). Research on managing groups and teams: Fairness and groups (pp. 239267). Bingley, UK: JAI Emerald.

Schat, A., \& Kelloway, E.K. (2003). Reducing the adverse consequences of workplace aggression and violence: The buffering effects of organizational support. Journal of Occupational Health Psychology, 8, 110-122.

Schlenker, B. R., \& Britt, T. W. (2001). Strategically controlling information to help friends: Effects of empathy and friendship strength on beneficial impression management. Journal of Experimental Social Psychology, 37, 357-372.

Schnall, S., Benton, J., \& Harvey, S. (2008). With a clean conscience: Cleanliness reduces the severity of moral judgments. Psychological Science, 19, 1219-1222. 
Schwab, D. P. (1980). Construct validity in organizational behavior. In B. M. Staw \& L. L. Cummings (Eds.), Research in organizational behavior: An annual series of analytical essays and critical reviews (pp. 3 - 43). Greenwich, CT: JAI Press

Sekerka, L.E., \& Bagozzi, R.P. (2007). Moral courage in the workplace: Moving to and from the desire and decision to act. Business Ethics: A European Review, 16, 132-149.

Sekerka, L.E., Bagozzi, R.P., \& Charnigo, R. (2009). Facing ethical challenges in the workplace: Conceptualizing and measuring professional moral courage. Journal of Business Ethics, 89, 565-579.

Shadish, W.R., Cook, T.D., \& Campbell, D.T. (2002). Experimental and quasi-experimental designs for generalized causal inference. Boston: Houghton-Mifflin.

Simons, T., \& Roberson, Q. (2003). Why managers should care about fairness: The effects of aggregate justice perceptions on organizational outcomes. Journal of Applied Psychology, 88, 432-443.

Simon, B., Stürmer, S., \& Steffens, K. (2000). Helping individuals or group members? The role of individual and collective identification in AIDS volunteerism. Personality and Social Psychology Bulletin, 26, 497-506.

Skarlicki, D. P., \& Kulik, C. (2005). Third party reactions to employee mistreatment: A justice perspective. In B. Staw \& R. Kramer (Eds.), Research in organizational behavior (183 230). Greenwich, CT: JAI Press.

Skarlicki, D.P., \& Rupp, D. (2010). Dual-processing and organizational justice: The role of rational versus experiential processing in third party reactions to workplace mistreatment. Journal of Applied Psychology, 95, 944-952. 
Skitka, L. J. (2002). Do the means always justify the ends or do the ends sometimes justify the means? A value protection model of justice reasoning. Personality and Social Psychology Bulletin, 28, 588-597.

Skitka, L. J., \& Mullen, E. (2002). Understanding judgments of fairness in a real-world political context: A test of the value protection model of justice reasoning. Personality and Social Psychology Bulletin, 28, 1419-1429.

Spell, C., \& Arnold, T. (2007). A multi-level analysis of organizational justice climate, structure and employee mental health. Journal of Management, 33, 724-751.

Stürmer, S., Snyder, M., \& Omoto, A. M. (2005). Prosocial emotions: The moderating role of group membership. Journal of Personality and Social Psychology, 88, 532-546.

Stürmer, S., Snyder, M., Kropp, A., \& Siem, B. (2006). Empathy-motivated helping: The moderating role of group membership. Personality and Social Psychology Bulletin, 32, 943-956.

Tajfel, H., \& Turner, J. C. (1986). The social identity theory of inter-group behavior. In S. Worchel \& L. W. Austin (Eds.), Psychology of intergroup relations (pp. 7-24). Chicago: Nelson-Hall.

Tedeschi, J. T., \& Norman, N. M. (1985). A social psychological interpretation of displaced aggression. Advances in Group Processes, 2, 29-56.

Tedeschi, J.T., \& Quigley, B.M. (1996). Limitations of laboratory paradigms for studying aggression. Aggression and Violent Behavior, 1, 163-177. 
Tett, R. P., \& Guterman, H. A. (2000). Situation trait relevance, trait expression, and crosssituational consistency: Testing a principle of trait activation. Journal of Research in Personality, 34, 397- 423.

Tett, R. P., \& Burnett, D. D. (2003). A personality trait-based interactionist model of job performance. Journal of Applied Psychology, 88, 500 -517.

Thau, S., Bennett, R.J., Mitchell, M.S., \& Marrs, M.B (2009). How management style moderates the relationship between abusive supervision and workplace deviance: An uncertainty management theory perspective. Organizational Behavior and Human Decision Processes, 108, 79-92.

Thau, S., \& Mitchell, M. S. (2010). Self-gain or self-regulation impairment? Tests of competing explanations of the supervisor abuse and employee deviance relationship through perceptions of distributive justice. Journal of Applied Psychology, 95, 1009-1031.

Tepper, B. J. (2000). Consequences of abusive supervision. Academy of Management Journal, 43, $178-190$.

Tepper, B. J. (2007). Abusive supervision in work organizations: Review, synthesis, and research agenda. Journal of Management, 33, 261-289.

Tepper, B. J., Duffy, M. K., \& Shaw, J. D. (2001). Personality moderators of the relationship between abusive supervision and subordinates’ resistance. Journal of Applied Psychology, 86, 974-983.

Tepper, B., Hoobler, J., Duffy, M.K., \& Ensley, M.D. (2004). Moderators of the relationships between coworkers’ organizational citizenship behavior and fellow employees’ attitude. Journal of Applied Psychology, 89, 455-465. 
Tepper, B. J., \& Lockhart, D. (2005). Abused subordinates’ upward maintenance communication: A coping perspective. Proceedings of the Annual Meeting of the Southern Management Association, Charleston, South Carolina.

Tepper, B. J., Duffy, M. K., Henle, C. A., \& Lambert, L. S. (2006). Procedural injustice, victim precipitation, and abusive supervision. Personnel Psychology, 59, 101-123.

Tepper, B. J., Henle, C. A., Lambert, L. S., Giacalone, R. A., \& Duffy, M. K. (2008). Abusive supervision and subordinates’ organization deviance. Journal of Applied Psychology, 93, 721-732.

Tepper, B. J., Carr, J., Breaux, D. M., Geider, S., Hu, C., \& Hua, W. (2009). Abusive supervision, intentions to quit, and employees' workplace deviance. Organizational Behavior and Human Decision Processes, 109, 156-167.

Tepper, B.J., Moss, S., \& Duffy, M.K. (2011). Antecedents of abusive supervision: Supervisor perceptions of deep-level dissimilarity, relationship conflict, and subordinate performance. Academy of Management Journal, 54, 279-294.

Turillo, C. J., Folger, R., Lavelle, J., Umphress, E., \& Gee, J. (2002). Is virtue its own reward? Self-sacrificial decisions for the sake of fairness. Organizational Behavior and Human Decision Processes, 89, 839-865.

Van den Bos, K., \& Lind, E. A. (2002). Uncertainty management by means of fairness judgments. In M. P. Zanna (Ed.), Advances in experimental social psychology (pp. 1-60). San Diego, CA: Academic Press.

Van Dyne, L., \& LePine, J. A. (1998). Helping and voice extra-role behavior: Evidence of construct and predictive validity. Academy of Management Journal, 41, 108-119. 
Wayment, H.A. (2004). It could have been me: Vicarious victims and disaster-focused distress. Personality and Social Psychology Bulletin, 30, 515-528.

Wayment, H. A., Silver, R. C., \& Kemeny, M. E. (1995). Spared at random: Survivor reactions in the gay community. Journal of Applied Social Psychology, 25, 187-209.

Wu, T.Y., \& Hu, C. (2009). Abusive supervision and employee emotional exhaustion: Dispositional antecedents and boundaries. Group \& Organization Management, 43, 143169.

Yagil, D. (2006). The relationship of abusive and supportive workplace supervision to employee burnout and upward influence tactics. Journal of Emotional Abuse, 6, 49-65.

Zapata-Phelan, C. P., Colquitt, J. A., Scott, B. A., \& Livingston, B. (2009). Procedural justice, interactional justice, and task performance: The mediating role of intrinsic motivation. Organizational Behavior and Human Decision Processes, 108, 93-105.

Zapf, D., \& Einarsen, S. (2001). Bullying in the workplace: Recent trends in research and practice - an introduction. European Journal of Work and Organizational Psychology, 10, 369-373.

Zellars, K.L., Tepper, B.J., \& Duffy, M.K. (2002). Abusive supervision and subordinates’ organizational citizenship behavior. Journal of Applied Psychology, 87, 1068-1076.

Zhong, C. B., \& Liljenquist, K. (2006). Washing away your sins: Threatened morality and physical cleansing. Science, 313, 1451-1452. 